\title{
Microphysical processing of aerosol particles in orographic clouds
}

\author{
S. Pousse-Nottelmann ${ }^{1,3}$, E. M. Zubler ${ }^{2}$, and U. Lohmann ${ }^{1,3}$ \\ ${ }^{1}$ Institute for Atmospheric and Climate Science, ETH Zurich, 8092 Zurich, Switzerland \\ ${ }^{2}$ Federal Office of Meteorology and Climatology MeteoSwiss, Operation Center 1, Zurich Airport, 8058 Zurich, Switzerland \\ ${ }^{3}$ Center for Climate Systems Modeling, ETH Zurich, 8092 Zurich, Switzerland
}

Correspondence to: S. Pousse-Nottelmann (sara.pousse@env.ethz.ch)

Received: 21 July 2014 - Published in Atmos. Chem. Phys. Discuss.: 27 January 2015

Revised: 14 June 2015 - Accepted: 21 July 2015 - Published: 20 August 2015

\begin{abstract}
An explicit and detailed treatment of cloud-borne particles allowing for the consideration of aerosol cycling in clouds has been implemented into COSMO-Model, the regional weather forecast and climate model of the Consortium for Small-scale Modeling (COSMO). The effects of aerosol scavenging, cloud microphysical processing and regeneration upon cloud evaporation on the aerosol population and on subsequent cloud formation are investigated. For this, twodimensional idealized simulations of moist flow over two bell-shaped mountains were carried out varying the treatment of aerosol scavenging and regeneration processes for a warmphase and a mixed-phase orographic cloud.

The results allowed us to identify different aerosol cycling mechanisms. In the simulated non-precipitating warm-phase cloud, aerosol mass is incorporated into cloud droplets by activation scavenging and released back to the atmosphere upon cloud droplet evaporation. In the mixed-phase cloud, a first cycle comprises cloud droplet activation and evaporation via the Wegener-Bergeron-Findeisen (WBF) process. A second cycle includes below-cloud scavenging by precipitating snow particles and snow sublimation and is connected to the first cycle via the riming process which transfers aerosol mass from cloud droplets to snowflakes. In the simulated mixed-phase cloud, only a negligible part of the total aerosol mass is incorporated into ice crystals. Sedimenting snowflakes reaching the surface remove aerosol mass from the atmosphere. The results show that aerosol processing and regeneration lead to a vertical redistribution of aerosol mass and number. Thereby, the processes impact the total aerosol number and mass and additionally alter the shape of the aerosol size distributions by enhancing the internally mixed/soluble Aitken and accumulation mode and generating coarse-mode particles. Concerning subsequent cloud for-
\end{abstract}

mation at the second mountain, accounting for aerosol processing and regeneration increases the cloud droplet number concentration with possible implications for the ice crystal number concentration.

\section{Introduction}

Orography has an important influence on precipitation formation and can be a key factor in hydrology, ecology and climate on the local scale (Smith et al., 2005; Saleeby et al., 2009). When air rises over sloped terrain, it cools. Above the lifting condensation level, the air becomes supersaturated with respect to water allowing for the formation of cloud droplets by condensation of water vapor onto cloud condensation nuclei $(\mathrm{CCN})$. In such a warm-phase cloud, precipitation can form via condensational growth and collisioncoalescence of cloud droplets. When temperatures fall below the freezing level, ice crystal formation is triggered by ice nuclei (IN), transforming the liquid cloud into a mixedphase cloud. Due to the difference in saturation vapor pressure over ice and over water, ice crystals can grow rapidly at the expense of evaporating cloud droplets when the vapor pressure is below water saturation. This process, known as the Wegener-Bergeron-Findeisen (WBF) process (Wegener, 1911; Bergeron, 1935; Findeisen, 1938), can lead to a rapid glaciation of a mixed-phase cloud at temperatures between -38 and $0{ }^{\circ} \mathrm{C}$. Below $-38^{\circ} \mathrm{C}$ the droplets start to freeze homogeneously.

Ice microphysical processes are of major interest, as $70 \%$ of tropical precipitation forms via the ice phase (Lau and $\mathrm{Wu}$, 2003). On the regional scale, heavy orographic precipitation events in the Alps have also been associated with ice-phase 
processes (Pujol et al., 2005), indicating the importance of the cold phase for precipitation formation.

Aerosol particles impact the cloud microphysical processes directly by serving as cloud condensation nuclei for the formation of cloud droplets and by initiating ice nucleation. They influence cloud development and properties and ultimately precipitation formation. However, the quantification of the aerosol effect on clouds remains challenging and represents one of the largest uncertainties in the climate system (Boucher et al., 2013).

Enhanced aerosol concentrations result in an increased number concentration of cloud droplets, shifting the droplet size spectrum towards smaller radii for a constant liquid water content (Twomey et al., 1974). Due to the reduced collision efficiencies of smaller droplets, the formation of rain is delayed and the cloud may persist for a longer time period (Albrecht, 1989).

In idealized simulations of purely warm-phase orographic precipitation, Muhlbauer and Lohmann (2008) observed that increased atmospheric aerosol concentrations lead to more but smaller cloud droplets producing a shift in precipitation towards the leeward side of the mountain (spillover effect). An investigation of orographic precipitation over the Sierra Nevada showed that polluted continental aerosol concentrations in comparison to clean marine aerosol conditions lead to a precipitation reduction on the upslope side of the mountains, decreasing the overall precipitation by about $30 \%$ (Lynn et al., 2007).

If ice processes are involved, the difference between clouds formed on marine vs. continental aerosol concentrations is even more pronounced (Lynn et al., 2007). Indeed, within mixed-phase cloud regimes, a decrease of the mean cloud droplet radius also implies a lessening of the riming efficiency between droplets and ice particles due to reduced collision efficiencies of smaller droplets (Lohmann, 2004). Saleeby et al. (2009) showed that in mixed-phase orographic clouds along the Park Range barrier in Colorado, enhanced $\mathrm{CCN}$ number concentrations modify the droplet distribution significantly, leading to a substantial inhibition of the riming process. At the same time, the WBF process is enhanced under polluted conditions because of the greater surface area exposure of more but smaller cloud droplets, largely compensating for the loss in snow growth by the reduced riming process (Saleeby et al., 2013).

Another important characteristic is the ice-nucleation ability of certain aerosol types. Depending on the composition and mixing state, a part of the aerosol population may potentially serve as ice nuclei and trigger heterogeneous freezing. Depending on the temperature and supersaturation with respect to water, different freezing modes have been identified (Vali, 1985). Zubler et al. (2011b) showed that the effect of an increased aerosol number concentration on orographic mixed-phase clouds strongly depends on the presence of the ice phase and particularly the heterogeneous freezing of droplets. In cold simulations, with aerosol parti- cles acting as $\mathrm{CCN}$ and as IN in the condensation/immersion freezing mode, the reduction of precipitation formation via the liquid phase due to smaller droplets is partly compensated by a glaciation of the clouds. The processes which are most affected by increased aerosol loadings are coalescence and riming (Muhlbauer and Lohmann, 2009), which are important pathways for precipitation formation.

Muhlbauer and Lohmann (2009) investigated the impact of dust and anthropogenic black carbon anomalies as potential ice nuclei on orographic mixed-phase clouds and pointed out the crucial role of the assumed aerosol properties. Due to the different onset temperatures and efficiencies of the different freezing modes, the ice phase may vary according to the dominant freezing process impacting riming rates and thus precipitation formation.

During their residence time in the atmosphere, aerosol particles undergo various modifications which may affect their ability to serve as CCN and IN. Thereby, aerosol processing within clouds plays a crucial role, as the aerosol mass, composition and mixing state can be altered. Due to activation, nucleation and collision-coalescence processes aerosol particles are incorporated into hydrometeors. Processes like autoconversion, accretion, aggregation, freezing, melting, riming and self-collection transfer aerosol mass and number between the different hydrometeor classes. Aqueous-phase chemistry within droplets can lead to the formation of new aerosol mass. Finally, wet deposition, sedimentation and scavenging processes lead to a removal of aerosol mass from the atmosphere. However, a substantial fraction of hydrometeors evaporate/sublimate, releasing newly formed aerosol particles to the atmosphere with different size, composition and mixing state compared to the original ones. Recent investigations concerning the impact of aerosol solubility and recycled aerosol particles on orographic cloud formation have been conducted by Xue et al. $(2010,2012)$. They explicitly account for the release of aerosol particles upon droplet and rain evaporation, replenishing between one-third and two-thirds of the scavenged aerosol particles. In their model configuration, the $\mathrm{CCN}$ number concentration explicitly depends on the number concentration and properties of the background and regenerated aerosol particles. In idealized 2-D simulations of warm-phase clouds over two bellshaped mountains, recycled aerosol particles enhance the cloud droplet number concentration and thus reduce precipitation formation at the second mountain (Xue et al., 2010). In mixed-phase clouds, regenerated aerosol particles were found to inhibit the riming process by changing the droplet size distribution (Xue et al., 2012).

In the atmosphere, however, cloud droplet activation and heterogeneous freezing processes may be affected by the release of processed aerosol particles. The ice-nucleation efficiency of aerosol particles in the different freezing modes depends on their size, composition and mixing state, which may be altered during cloud processing. The present study therefore explicitly considers both the droplet and ice nucle- 
ating ability of certain aerosol particles and their release back into the atmosphere upon evaporation/sublimation.

To better understand the role of aerosol-cloud interactions and especially the role of regenerated aerosol particles, COSMO-Model, the regional weather forecast and climate model currently developed and maintained by the Consortium for Small-scale Modeling (COSMO), has been extended in a detailed treatment of hydrometeor-borne aerosol particles following the approach by Hoose et al. (2008). The new scheme allows for the simulation of cloud cycling of aerosols by tracing them even when scavenged into hydrometeors.

The paper is structured as follows: in Sect. 2 we describe the employed cloud and aerosol microphysical parameterizations with a focus on aerosol-cloud interactions. In Sect. 3 we introduce the simulation setup before presenting the results for warm-phase clouds in Sect. 4.1 and mixed-phase clouds in Sect. 4.2. In Sect. 5 we end with a summary of our results and conclusions.

\section{Numerical model description}

This study makes use of COSMO-Model (http://www. cosmo-model.org), a non-hydrostatic, fully compressible weather prediction and climate model. This limited-area mesoscale atmospheric prediction model integrates the elastic hydro-thermodynamical equations on a rotated Arakawa C-grid with a time-splitting approach following a splitexplicit third-order Runge-Kutta scheme in combination with a fifth-order upstream horizontal advection scheme (Doms and Schättler, 2002; Steppeler et al., 2003). The aerosol and moisture variables are advected by the secondorder positive-definite Bott scheme (Bott, 1989).

\subsection{Cloud microphysics}

Cloud microphysical processes are calculated within the two-moment bulk cloud microphysics scheme for water and ice clouds of Seifert and Beheng (2006). The scheme comprises prognostic equations for the mass and number densities of five different hydrometeor classes: cloud droplets, ice crystals, raindrops, snowflakes and graupel. Warm-phase cloud processes include activation of cloud droplets, condensational growth and evaporation of cloud droplets, autoconversion (formation of rain by coagulating cloud droplets) and accretion (growth of raindrops by collection of cloud droplets), self-collection (mutual coagulation of cloud droplets/raindrops, remaining in the same drop category), evaporation of rain and collisional break-up of large raindrops. In colder regimes, the scheme also accounts for homogeneous and heterogeneous freezing, diffusional growth of ice crystals, aggregation (formation of snow by coagulating ice crystals), self-collection (mutual coagulation of ice/snow/graupel, remaining in the same hydrometeor category), riming (coagulation between the liquid and the ice phase), melting and sublimation and related secondary processes. The Wegener-Bergeron-Findeisen process is represented implicitly in the model because in an air parcel, which is supersaturated with respect to ice but subsaturated with respect to water, all condensate evaporates and the ice crystals grow by water diffusion. The parameterization of hydrometeor sedimentation is based on mass- and number-weighted mean fall velocities.

\subsection{Aerosol microphysics}

\subsubsection{The M7 aerosol module}

The cloud microphysics scheme is coupled to the M7 aerosol module (Vignati et al., 2004; Muhlbauer and Lohmann, 2008, 2009; Zubler et al., 2011a) which is also used within the framework of the general circulation model system ECMWF Hamburg Model (ECHAM5-HAM) (Stier et al., 2005). The M7 aerosol module describes the aerosol population as a superposition of seven lognormal size distributions of the form

$N(\ln r)=\sum_{k=1}^{7} \frac{N_{k}}{\sqrt{2 \pi} \ln \sigma_{k}} \exp \left[-\left(\frac{\ln r-\ln \overline{r_{k}}}{\sqrt{2} \ln \sigma_{k}}\right)^{2}\right]$.

Here, $N_{k}$ represents the aerosol number concentration of the $k$ th aerosol mode with $k \in[1,7]$ and $\sigma_{k}$ is the corresponding geometric standard deviation. In M7, the aerosol number and mass concentrations are prognostic variables whereas the standard deviations are kept constant.

The module distinguishes between four internally mixed, soluble modes (nucleation, Aitken, accumulation, and coarse mode), containing both soluble and insoluble compounds, and three insoluble modes (Aitken, accumulation, and coarse mode), which are characterized by low water solubility. It accounts for five different aerosol compounds: sulfate (SU), carbonaceous aerosols (black carbon $\mathrm{BC}$, organic carbon OC), sea salt (SS) and mineral dust (DU) (Table 1). Due to sulfate coating or coagulation, insoluble particles, containing externally mixed freshly formed (black) carbon and dust, can be transferred to the internally mixed modes. The aerosol scheme accounts for nucleation of gas-phase sulfuric acid (Vehkamäki et al., 2002), condensation of sulfuric acid on pre-existing aerosol particles, coating of insoluble aerosol particles with sulfuric acid, inter- and intramodal coagulation and water vapor uptake. The M7 aerosol module does not account for nitrate and ammonium aerosol components as it does not include a treatment of the thermodynamic equilibration of these semi-volatile aerosol compounds with the gas phase. However, these constituents may represent an important part of the aerosol population and modify the surface properties of other aerosol particles due to coatings increasing aerosol growth and activation to cloud droplets. This work represents the aerosol population with the modal approach which is computationally cheaper than the sectional approach and allows one to conduct 3-D long-term simulations. Comparing the modal and sectional approach 
Table 1. Table of the different aerosol modes of the aerosol module M7. The size range of each mode is given for the count median radius $\overline{r_{k}} \cdot N_{k}$ and $M_{k}^{X}$ correspond to the aerosol number and mass density for the mode $k \in[1,7]$ and compound $X \in\{\mathrm{SU}, \mathrm{BC}, \mathrm{OC}, \mathrm{SS}, \mathrm{DU}\}$ respectively. Adapted from Vignati et al. (2004).

\begin{tabular}{lcll}
\hline $\begin{array}{l}\text { Aerosol } \\
\text { mode }\end{array}$ & $\begin{array}{c}\text { Size range } \\
{[\mu \mathrm{m}]}\end{array}$ & Soluble/internally mixed mode & Insoluble modes \\
\hline Nucleation & $<0.005$ & $N_{1}, M_{1}^{\mathrm{SU}}$ & \\
Aitken & $0.005-0.05$ & $N_{2}, M_{2}^{\mathrm{SU}}, M_{2}^{\mathrm{BC}}, M_{2}^{\mathrm{OC}}$ & $N_{5}, M_{5}^{\mathrm{BC}}, M_{5}^{\mathrm{OC}}$ \\
Accumulation & $0.05-0.5$ & $N_{3}, M_{3}^{\mathrm{SU}}, M_{3}^{\mathrm{BC}}, M_{3}^{\mathrm{OC}}, M_{3}^{\mathrm{SS}}, M_{3}^{\mathrm{DU}}$ & $N_{6}, M_{6}^{\mathrm{DU}}$ \\
Coarse & $>0.5$ & $N_{4}, M_{4}^{\mathrm{SU}}, M_{4}^{\mathrm{BC}}, M_{4}^{\mathrm{OC}}, M_{4}^{\mathrm{SS}}, M_{4}^{\mathrm{DU}}$ & $N_{7}, M_{7}^{\mathrm{DU}}$ \\
\hline
\end{tabular}

in a global 3-D model, Mann et al. (2012) found that differences between the two approaches were less than modelobservation differences. However, they underlined that the size-resolved aerosol properties in modal schemes need to be benchmarked and improved against sectional schemes and observations. Applying a two-moment aerosol bulk microphysics scheme with an explicit treatment of aerosol activation and scaled rates for the other microphysical processes, Lebo and Morrison (2013) obtained similar results between the modal and the sectional approach. The explicit parameterizations of aerosol activation and below-cloud scavenging processes in our model were evaluated against observations by Zubler et al. (2011a).

\subsubsection{The aerosol processing scheme}

To simulate aerosol processing in clouds, five new aerosol modes corresponding to the five prognostic hydrometeor classes (in-cloud droplet (CD), in-ice crystal (IC), inraindrop (RD), in-snowflake (SF) and in-graupel (GR) aerosol mode; Table 2) are introduced into the model. Following the approach of Hoose et al. (2008), these new modes contain hydrometeor-borne aerosol mass, potentially consisting of a contribution of all five aerosol components (SU, BC, OC, SS, DU). The number densities of hydrometeor-borne aerosol particles are not prognostic variables, but diagnosed from the corresponding hydrometeor number density during evaporation and sublimation. The new modes are not limited by any specific size range. Their median radii are calculated directly upon evaporation/sublimation (Eq. 5). Aerosol activation scavenging, collision/impaction scavenging as well as sulfate production within droplets lead to an increase of the in-hydrometeor aerosol mass. In the standard version of the model as described by Muhlbauer and Lohmann (2008), the M7 aerosol module comprises the total aerosol population, including interstitial particles within the cloud, unactivated particles in cloud free air and activated in-hydrometeor aerosols. In the new model version presented here, only interstitial or unactivated aerosol particles are assigned to the M7 module. All material which is taken up by a hydrometeor is transferred to the new modes CD, IC, RD, SF and GR.
Aerosol particles are incorporated into hydrometeors due to the different scavenging processes, including activation of aerosol particles, in-cloud impaction scavenging and belowcloud scavenging by precipitating hydrometeors. Once inside a hydrometeor, the aerosol particles undergo the cloud microphysical processes along with the hydrometeors. Upon evaporation and sublimation, the in-hydrometeor aerosol mass is released to the atmosphere forming a newly generated aerosol particle. To allow for coagulation, sedimentation, activation and scavenging of the processed aerosol particles together with the unactivated background aerosol, processed and background aerosol are summed up loosing valuable information about their specific size distributions and composition. When falling hydrometeors reach the ground, the hydrometeor-borne aerosol mass is directly removed from the system. These processes and the corresponding transfer of aerosol mass are illustrated in Fig. 1.

\subsection{Aerosol-cloud interactions}

In order to simulate aerosol-cloud interactions, the aerosol module has been coupled to the cloud microphysics scheme following the approach by Stier et al. (2005) as described in Muhlbauer and Lohmann (2008). In this standard version of the model, the aerosol number concentrations influence the cloud properties, but are not affected themselves by the clouds.

The new aerosol processing scheme tracks aerosol particles even when incorporated into hydrometeors. The aerosol module M7, the cloud microphysics scheme, and the five inhydrometeor aerosol modes are directly coupled in order to allow for the simulation of cloud cycling of aerosol particles. This enables to consider the interactions between aerosols and clouds in a complete way. 
Table 2. Table of the five in-hydrometeor aerosol modes. $M_{j}^{X}$ corresponds to the in-hydrometeor aerosol mass density for the mode $j \in$ $\{\mathrm{CD}, \mathrm{RD}, \mathrm{IC}, \mathrm{SF}, \mathrm{GR}\}$ and compound $X \in\{\mathrm{SU}, \mathrm{BC}, \mathrm{OC}, \mathrm{SS}, \mathrm{DU}\}$. The number mode $N_{j}$ with $j \in\{\mathrm{CD}, \mathrm{RD}, \mathrm{IC}, \mathrm{SF}, \mathrm{GR}\}$ is not a prognostic variable, but is diagnosed during evaporation and sublimation from the corresponding hydrometeor number density.

\begin{tabular}{llll}
\hline Aerosol mode & Abbrev. & Mass modes & Number mode \\
\hline In-cloud droplet mode & $\mathrm{CD}$ & $M_{\mathrm{CD}}^{\mathrm{SU}}, M_{\mathrm{CD}}^{\mathrm{BC}}, M_{\mathrm{CD}}^{\mathrm{OC}}, M_{\mathrm{CD}}^{\mathrm{SS}}, M_{\mathrm{CD}}^{\mathrm{DU}}$ & $N_{\mathrm{CD}}=N_{\mathrm{c}}$ \\
In-raindrop mode & $\mathrm{RD}$ & $M_{\mathrm{RD}}^{\mathrm{SU}}, M_{\mathrm{RD}}^{\mathrm{BC}}, M_{\mathrm{RD}}^{\mathrm{OC}}, M_{\mathrm{RD}}^{\mathrm{SS}}, M_{\mathrm{RD}}^{\mathrm{DU}}$ & $N_{\mathrm{RD}}=N_{\mathrm{r}}$ \\
In-ice crystal mode & $\mathrm{IC}$ & $M_{\mathrm{IC}}^{\mathrm{SU}}, M_{\mathrm{IC}}^{\mathrm{BC}}, M_{\mathrm{IC}}^{\mathrm{OC}}, M_{\mathrm{IC}}^{\mathrm{SS}}, M_{\mathrm{IC}}^{\mathrm{DU}}$ & $N_{\mathrm{IC}}=N_{\mathrm{i}}$ \\
In-snowflake mode & $\mathrm{SF}$ & $M_{\mathrm{SF}}^{\mathrm{SU}}, M_{\mathrm{SF}}^{\mathrm{BC}}, M_{\mathrm{SF}}^{\mathrm{OC}}, M_{\mathrm{SF}}^{\mathrm{SS}}, M_{\mathrm{SF}}^{\mathrm{DU}}$ & $N_{\mathrm{SF}}=N_{\mathrm{s}}$ \\
In-graupel mode & $\mathrm{GR}$ & $M_{\mathrm{GR}}^{\mathrm{SU}}, M_{\mathrm{GR}}^{\mathrm{BC}}, M_{\mathrm{GR}}^{\mathrm{OC}}, M_{\mathrm{GR}}^{\mathrm{SS}}, M_{\mathrm{GR}}^{\mathrm{DU}}$ & $N_{\mathrm{GR}}=N_{\mathrm{g}}$ \\
\hline
\end{tabular}

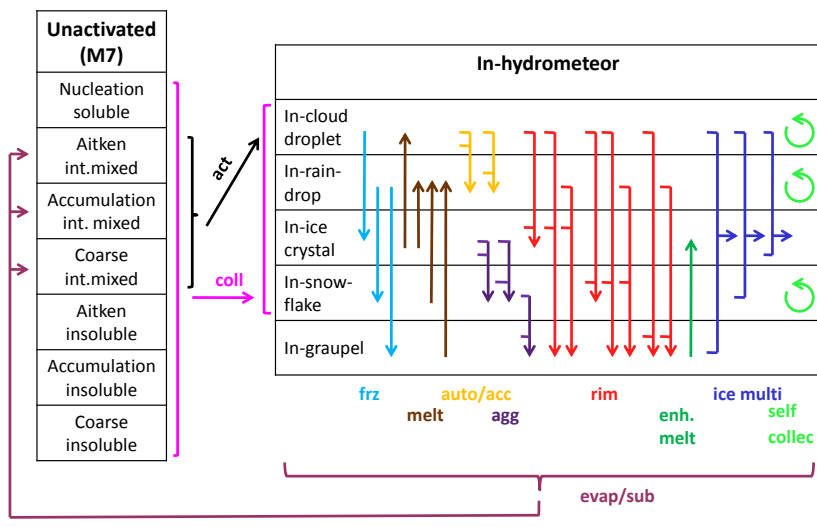

Figure 1. Microphysical transfer processes between the different aerosol modes (coll represents in-cloud and below-cloud collision scavenging, act represents activation scavenging, frz represents freezing, melt represents melting, auto represents autoconversion, acc represents accretion, agg represents aggregation, rim represents riming, enh. melt represents enhanced melting, ice multi represents ice multiplication, self collec represents self-collection, evap represents evaporation, sub represents sublimation).

\subsubsection{Activation of cloud droplets}

In the present model version the activation of cloud droplets is parameterized according to the approach by Lin and Leaitch (1997) following the works by Muhlbauer and Lohmann (2008) and Zubler et al. (2011a). The number of newly activated cloud droplets is based on the number concentration of soluble/mixed aerosol particles larger than $35 \mathrm{~nm}\left(N_{>35 \mathrm{~nm}}\right)$ and the updraft vertical velocity $w$ and is given by

$$
\begin{aligned}
& \frac{\partial N_{\mathrm{c}}}{\partial t}= \\
& \max \left\{\frac{1}{\Delta t}\left[0.1\left(\frac{w N_{>35 \mathrm{~nm}}^{t}}{w+\alpha N_{>35 \mathrm{~nm}}^{t}}\right)^{1.27}-N_{\mathrm{c}}^{t-1}\right], 0\right\},
\end{aligned}
$$

with $\alpha=0.023 \mathrm{~cm}^{4} \mathrm{~s}^{-1}$ and $N_{\mathrm{c}}$ the number of activated cloud droplets. The simulated vertical velocity may not reach high enough values to realistically represent local updrafts when averaged over the entire grid box, especially in simulations with lower horizontal resolution. Therefore, the updraft velocity $w$ is calculated as the sum of the grid-scale velocity $w_{\mathrm{g}}$ and a subgrid-scale turbulent contribution. Following the approach of Lohmann (2002), the turbulent part depends on the turbulent kinetic energy (TKE) yielding for the updraft velocity

$w=w_{\mathrm{g}}+c_{\text {turb }} \sqrt{\mathrm{TKE}}, \quad c_{\text {turb }}=1.33$.

To be consistent with the standard parameterization of cloud droplet activation in the model we maintain this calculation of the updraft velocity in our simulations though not imperative at a horizontal resolution of $2 \mathrm{~km}$.

$N_{>35 \mathrm{~nm}}$ is the number concentration of possible CCN particles containing all soluble/mixed aerosols in the coarse $\left(N_{4}\right)$ and accumulation modes $\left(N_{3}\right)$ plus the number of mixed Aitken-mode particles $\left(N_{2}\right)$ with a wet radius larger than $r_{\text {crit }}=35 \mathrm{~nm}$ such that

$N_{>35 \mathrm{~nm}}=N_{4}+N_{3}+\int_{\ln \left(r_{\text {crit }}\right)}^{\infty} N_{2}(\ln r) \mathrm{d} \ln r$.

Insoluble particles and particles smaller than $35 \mathrm{~nm}$ cannot act as cloud condensation nuclei. When aerosol activation scavenging is considered, the number and mass of newly activated aerosol particles are removed from the M7 aerosol module. We assume that activation scavenging progresses from the biggest to the smallest particle in each mode. Following Zubler et al. (2011a) the scavenged mass of each species in each mode corresponds to the lognormal tail of the size distribution and is calculated using a critical radius. Scavenging thus causes a deviation from the log-normal aerosol modes that is lost when the new log-normal size distribution with reduced number concentration and mode radius is calculated. Considering only scavenging processes without applying the aerosol processing scheme, activation scavenging implies the removal of the scavenged aerosols from the system. When the aerosol processing scheme is ap- 
plied, it transfers the scavenged aerosol mass from the unactivated aerosol modes in the M7 module to the in-cloud droplet aerosol mode. In the standard version of the model, no activation scavenging is considered.

\subsubsection{Heterogeneous freezing processes}

Regarding heterogeneous nucleation of ice crystals, the model accounts for freezing in condensation/immersion and in contact mode (Muhlbauer and Lohmann, 2009), neglecting deposition nucleation due to the prevailing water saturation in mixed-phase clouds. The parameterization of immersion-mode freezing derived from Diehl and Wurzler (2004) and Lohmann and Diehl (2006) is based on the stochastic hypothesis considering that immersed aerosol particles can enhance the efficiency of random ice nucleation in a droplet, but do not disturb its stochastic nature. For immersion freezing, we consider soluble mixed black carbon (BC) and mineral dust (DU) as efficient ice nuclei dependent on a material-specific, size-dependent freezing efficiency and on the surface area fraction (Muhlbauer and Lohmann, 2009). Heterogeneous freezing in the contact mode is parameterized following the approaches of Young (1974a), Cotton et al. (1986) and Lohmann and Diehl (2006). The freezing process is assumed to be induced by collisions between supercooled water droplets and aerosol particles by Brownian diffusion (Muhlbauer and Lohmann, 2009). We consider insoluble (hydrophobic) black carbon (BC) and mineral dust (DU) as potential nuclei for contact freezing (Diehl et al., 2006). The Brownian diffusivity decreases with increasing particle size, leading to variations of the collision efficiency of several orders of magnitude between small and larger atmospheric aerosol particles.

\subsubsection{Collision scavenging}

The new model version further considers scavenging of aerosol particles by collision with hydrometeors. In-cloud collision scavenging refers to collision-coalescence of aerosol particles with cloud droplets or ice crystals. The parameterization of the collision rate depends on prescribed collision kernels estimated by Young (1974b), the aerosol number concentration and the cloud droplet (ice crystal) number concentration. Collision scavenging by sedimenting rain or snow is called below-cloud scavenging. The parametrization is based on the scavenging coefficient following the equations in Zhao and Zheng (2006) and Croft et al. (2009), as described by Zubler et al. (2011a). In order to consider only the final removal of aerosol particles from the atmosphere by surface reaching hydrometeors, Zubler et al. (2011a) multiplied the rate change of the tracer mass and number densities due to scavenging by rain (or snow) by the fraction of precipitating rain (or snow) reaching the surface. Scavenging by falling graupel is omitted. In the new aerosol processing scheme, all precipitating raindrops and snowflakes, not only surfacereaching hydrometeors, may scavenge aerosol particles. In this scheme, the scavenging coefficients are thus independent from the fraction of surface reaching precipitation. The scavenged aerosol mass is attributed to the corresponding inhydrometeor aerosol-mode $M_{\mathrm{CD}}^{X}$ or $M_{\mathrm{IC}}^{X}$ for in-cloud collision scavenging and $M_{\mathrm{RD}}^{X}$ or $M_{\mathrm{SF}}^{X}$ for below-cloud scavenging with $X \in\{\mathrm{SU}, \mathrm{BC}, \mathrm{OC}, \mathrm{SS}, \mathrm{DU}\}$. The standard version of the model does not account for collision scavenging.

\subsubsection{Evaporation/sublimation of hydrometeors}

During evaporation and sublimation of hydrometeors, aerosol particles are released back to the atmosphere. Inhydrometeor aerosol mass and the corresponding hydrometeors are transported the same way. Within one model time step, hydrometeors may also fall through several vertical model layers as the sedimentation flux calculations are done on a smaller time step. We scale the in-hydrometeor sedimentation flux according to the sedimentation flux of the corresponding hydrometeor. Therefore, the locations of evaporation/sublimation and the release of a new aerosol particles upon evaporation/sublimation coincide. The emitted aerosol particles are assumed to not break up (Mitra et al., 1992) and we presume that they contain a mixture of all foreign material in the hydrometeor as suggested by the homogeneous mixing assumption. Due to sulfate production in the aqueous phase, all processed particles contain some sulfate mass and therefore are attributed to the unactivated internally mixed/soluble modes. Adopting lognormal size distributions for the newly formed aerosols, the dry median radius is calculated following Hoose et al. (2008) such that

$$
\begin{gathered}
\bar{r}_{j}=\sqrt[3]{\frac{3}{4 \pi} \frac{V_{j}^{\text {tot }}}{N_{j}} \frac{1}{\exp \left(1.5 \ln ^{2} \sigma_{j}\right)},} \\
j \in\{\mathrm{CD}, \mathrm{IC}, \mathrm{RD}, \mathrm{SF}, \mathrm{GR}\}
\end{gathered}
$$

$N_{j}$ denotes the number density of potentially released aerosol particles (equal to the number density of the corresponding hydrometeors) and $\sigma_{j}$ is the geometric standard deviation of the size distribution being fixed to the value of the corresponding unactivated aerosol mode. $V_{j}^{\text {tot }}$ represents the total in-hydrometeor volume of aerosol mass within the grid box as given by

$V_{j}^{\mathrm{tot}}=\sum_{l} \frac{M_{j}^{X}}{\rho_{X}}, \quad X \in\{\mathrm{SU}, \mathrm{BC}, \mathrm{OC}, \mathrm{SS}, \mathrm{DU}\}$.

The dry densities of the compounds are given by $\quad \rho_{\mathrm{SU}}=1.841 \mathrm{~g} \mathrm{~cm}^{-3}, \quad \rho_{\mathrm{BC}}=\rho_{\mathrm{OC}}=2.0 \mathrm{~g} \mathrm{~cm}^{-3}$, $\rho_{\mathrm{SS}}=2.165 \mathrm{~g} \mathrm{~cm}^{-3}$ and $\rho_{\mathrm{DU}}=2.65 \mathrm{~g} \mathrm{~cm}^{-3}$ (Hoose et al., 2008). The released aerosol particle is added to the unactivated soluble mixed mode with $\bar{r}_{\mathrm{m}}$ falling in its size range (Table 1). 


\section{Model setup}

The present study focuses on the simulation of moist flow over two bell-shaped mountains in order to investigate the influence of processed aerosols on orographic cloud formation. The setup is based on the works of Muhlbauer and Lohmann (2008) and Muhlbauer et al. (2010). The twodimensional computational domain comprises 500 horizontal grid points with a grid spacing of $2 \mathrm{~km}$ yielding a domain size of $1000 \mathrm{~km}$. In the vertical, 50 levels follow hybrid height-based Gal-Chen coordinates from the surface to the top of the computational domain at $22 \mathrm{~km}$. The vertical grid spacing varies between $10 \mathrm{~m}$ for the lowest model level and $1000 \mathrm{~m}$ for the highest level. The model time step is $10 \mathrm{~s}$. At the bottom of the domain we impose a free-slip boundary condition. To minimize the reflection of gravity waves from the upper model boundary, a Rayleigh damping sponge layer fills the upper part of the computational domain beginning at an altitude of $11 \mathrm{~km}$. The idealized topography consists of two identical bell-shaped mountains, each following the form given by Kirshbaum and Durran (2004):

$h(x)= \begin{cases}\frac{h_{0}}{16}\left[1+\cos \left(\pi \frac{x-x_{i}}{4 a}\right)\right]^{4}, & \left|x-x_{i}\right|<4 a \\ 0, & \left|x-x_{i}\right|>4 a\end{cases}$

with $h_{0}=800 \mathrm{~m}$ the mountain peak height, $a=20 \mathrm{~km}$ the mountain half-width and $x_{i}$ the horizontal position of the mountain peak with $i \in\{1,2\}$. The two mountain peaks are located at $x_{1}=600 \mathrm{~km}$ and $x_{2}=800 \mathrm{~km}$, implying a distance of $200 \mathrm{~km}$ between the two mountain peaks. In the present setup, aerosol particles may be processed by the cloud over the first mountain, and then advected towards the second mountain where the processed aerosol particles potentially influence further cloud formation.

\subsection{Dynamical initialization}

The temperature and humidity profiles are initialized following the work of Muhlbauer and Lohmann (2008). The initial temperature profile is calculated analytically following Clark and Farley (1984) based on the sea-level pressure $p_{\mathrm{SL}}$, sea-level temperature $T_{\mathrm{SL}}$ and dry Brunt-Väisälä frequency $N_{\mathrm{d}}$. The sea-level pressure is fixed to $p_{\mathrm{SL}}=1000 \mathrm{hPa}$ and the dry Brunt-Väisälä frequency is prescribed vertically constant with $N_{\mathrm{d}}=0.011 \mathrm{~s}^{-1}$ (Muhlbauer et al., 2010). The sea-level temperature varies between $T_{\mathrm{SL}}=280 \mathrm{~K}$ and $T_{\mathrm{SL}}=270 \mathrm{~K}$ to allow for the formation of warm-phase and mixed-phase clouds. The relative humidity profile is calculated using a modified Fermi function (Spichtinger, 2004) given by

$\mathrm{RH}(z)=a+\frac{b-a}{1+\exp \left(-c\left(z-z_{0}\right)\right)}$,

with the parameters $a=0.90, b=0.03, c=0.0015 \mathrm{~m}^{-1}$ and $z_{0}=5000 \mathrm{~m}$. At the surface, the prescribed relative humidity

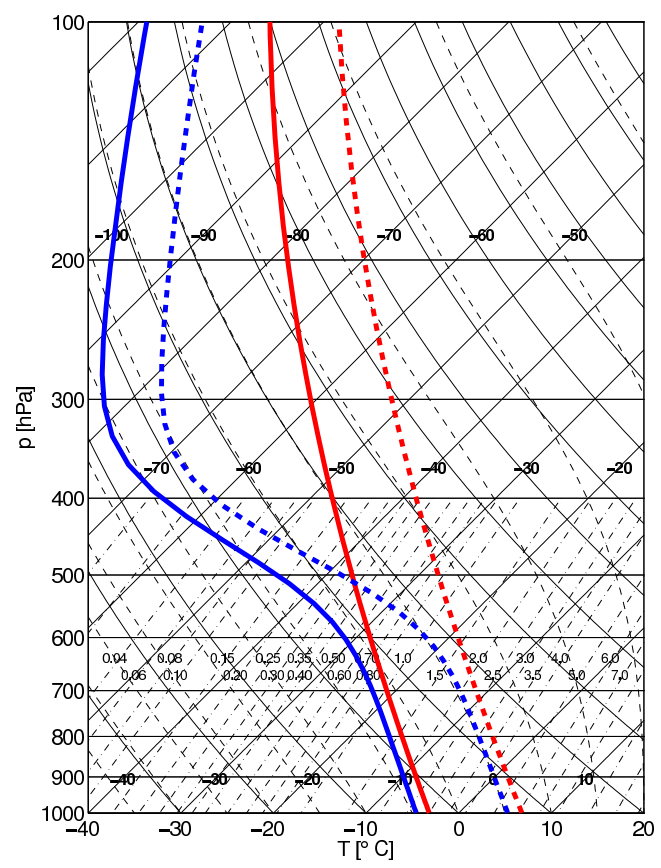

Figure 2. Skew-T-log-P diagram of the atmospheric soundings for the idealized 2-D simulations showing the temperature (red) and the dew point temperature (blue) with a surface relative humidity of $90 \%$. The warm sounding (dashed) with a surface temperature of $280 \mathrm{~K}$ is used for the simulation of a warm-phase cloud and the cold sounding (solid) with a surface temperature of $270 \mathrm{~K}$ is used for the simulation of a mixed-phase cloud.

profile has a value of $\mathrm{RH}=0.90$ which smoothly decreases with height to a value of $\mathrm{RH}=0.03$. The corresponding vertical profiles of temperature (red) and dew point temperature (blue) are shown in Fig. 2. Solid lines indicate the cold profiles and dashed lines indicate the warm profiles. Following the setup of Muhlbauer et al. (2010) the horizontal wind speed $U$ is vertically constant with $15 \mathrm{~ms}^{-1}$ up to an altitude of $10 \mathrm{~km}$. It then increases linearly with height up to $40 \mathrm{~ms}^{-1}$ at the top of the model domain. The initial conditions as specified yield a dimensionless mountain height $N_{\mathrm{d}} h_{0} / U=0.59$. According to theoretical considerations of dry flow over topographies (e.g., Durran, 1990), one thus expects an unblocked regime with flow over the ridge and associated formation of gravity waves. In our simulations, however, the dynamics of the flow will be modified by latent heat release resulting from condensation. As we focus on microphysical effects only, the complexity of this aerosol-cloud interaction study is reduced by turning off the radiation scheme and the convection parameterization.

\subsection{Aerosol initialization}

The initial aerosol number concentrations are prescribed based on observations in order to simulate realistic atmospheric aerosol conditions (Fig. 3). The aerosol number 
Table 3. Parameters of the initial aerosol size distributions (Muhlbauer and Lohmann, 2008) and mass fractional composition (Cozic et al., 2008) with $N_{\mathrm{a}}$ the aerosol number density, $r$ the mode mean radius, $\sigma$ the standard deviation and $M_{\mathrm{a}}$ the aerosol mass density of the lognormal distribution. Aerosol compounds include organic carbon (OC), black carbon (BC), sulfate (SU) and dust (DU).

\begin{tabular}{lccccl}
\hline Aerosol mode & $N_{\mathrm{a}}$ & $r$ & $\sigma$ & $M_{\mathrm{a}}$ & \multicolumn{1}{l}{ Mass fractional composition } \\
\hline Aitken & $530 \mathrm{~cm}^{-3}$ & $0.022 \mu \mathrm{m}$ & 2.13 & $0.27 \mu \mathrm{g} \mathrm{m}^{-3}$ & $66 \%$ OC, 30 \% SU, 4\% BC \\
Accumulation & $260 \mathrm{~cm}^{-3}$ & $0.070 \mu \mathrm{m}$ & 1.61 & $1.74 \mu \mathrm{g} \mathrm{m}^{-3}$ & $60 \%$ OC, 28 \% SU, 9\% DU, 3\% BC \\
\hline
\end{tabular}
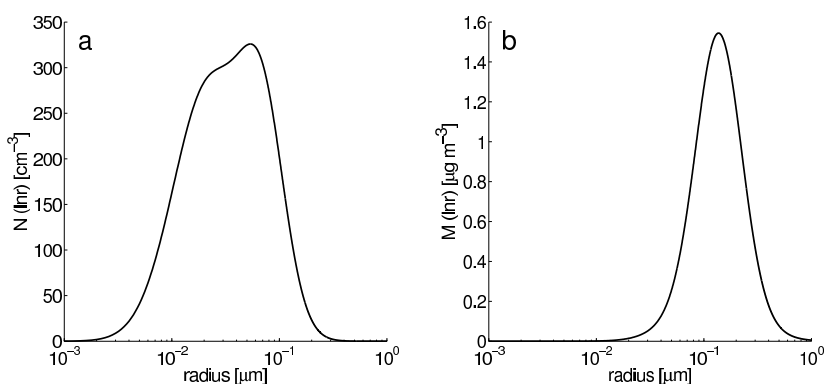

Figure 3. Initial aerosol (a) number density and (b) mass density size distributions for all simulations.

concentrations are compiled from measurement data collected by a scanning mobility particle sizer (SMPS) during a field campaign in 1999 at the high Alpine research station Jungfrauchjoch (Weingartner et al., 1999). Throughout this study we use the average summertime aerosol size distribution as described by Muhlbauer and Lohmann (2008), which is representative of planetary boundary layer air in the Alpine region. During the summer months, convective processes and local circulations allow for the transport of boundary layer air including local anthropogenic emissions to the free troposphere (Weingartner et al., 1999). The initial aerosol composition is based on observations of aerosol mass spectrometry at the same location (see Fig. 11 in Cozic et al., 2008). Aerosol particles are internal mixtures of black carbon (BC), organic carbon (OC), sulfate (SU) and dust (DU). The first three compounds are, besides nitrates, frequently observed in central Switzerland (Hueglin et al., 2005). Dust can be occasionally observed at the Jungfraujoch during intense Saharan dust events (Cozic et al., 2008; Chou et al., 2011). The aerosol number and mass concentrations are set as constant with height based on the parameters for the aerosol size distributions given in Table 3 .

Sulfate nucleation-mode particles are formed by gas-toparticle conversion from gas-phase sulfuric acid at low temperatures. Due to their small size, these particles cannot be measured by the SMPS. The vertical profiles of gaseous sulfate and the nucleation-mode aerosol particles are therefore initialized with averaged pseudo-soundings taken from the global circulation model ECHAM5-HAM (Stier et al., 2005) for the nearest Jungfraujoch grid point as described by Muhlbauer and Lohmann (2008).
To investigate the impact of aerosol processing and regeneration on the aerosol size distribution and further cloud formation, we vary the complexity of the representation of aerosol processes within the model (Table 4). The control simulations, CTL-w and CTL-c, employ the standard version of the aerosol module M7 without any scavenging processes (Muhlbauer and Lohmann, 2008, 2009) for the warm (w) and cold (c) cases, respectively. The simulations SCAV-w and SCAV-c include aerosol activation scavenging and belowcloud scavenging as described by Zubler et al. (2011a). In the simulations AP-w and AP-c we explicitly account for the new aerosol processing scheme including detailed aerosol activation, in-cloud and below-cloud scavenging processes, aerosol processing in clouds and aerosol regeneration upon hydrometeor evaporation and sublimation as described in the model section of this paper. To isolate the effect of aerosol regeneration, we additionally conduct simulations with the same parameterizations of the scavenging processes as in simulation AP-w and AP-c, but without aerosol regeneration (SCAV-ALL-w and SCAV-ALL-c).

\section{Results}

The following analyses are conducted after $10 \mathrm{~h}$ of simulation time, when a steady flow has been established and processed air masses from the first mountain pass over the second mountain. After $10 \mathrm{~h}$, a hydrostatic mountain wave has developed with upstream regions of flow deceleration and downstream regions of flow acceleration. The upstream region is characterized by almost horizontal isentropes while the gravity wave generates foehn-like winds on the leeward side of the ridge.

\subsection{Warm-phase cloud}

This section focuses on the simulations initialized with the warm temperature profile with a surface temperature of $280 \mathrm{~K}$. Similar dynamical conditions in all four simulations lead to the formation of warm-phase orographic clouds on the upslope side of the mountains with comparable liquid water mixing ratios (not shown). In the control simulation CTL-w, the cloud water mixing ratio has a maximum value of $0.97 \mathrm{~g} \mathrm{~kg}^{-1}$ over the mountain ridge (Fig. 4), whereas the rainwater mixing ratio does not exceed $0.01 \mathrm{~g} \mathrm{~kg}^{-1}$ (not shown). In the other simulations comparable values are pro- 
Table 4. Description of the conducted simulations.

\begin{tabular}{|c|c|c|c|}
\hline Simulation & Temperature & Aerosol initialization & Description \\
\hline CTL-w & $280 \mathrm{~K}$ & all aerosols mixed & standard simulation (Muhlbauer and Lohmann, 2008, 2009) \\
\hline SCAV-w & $280 \mathrm{~K}$ & all aerosols mixed & with aerosol activation and below-cloud scavenging (Zubler et al., 2011a) \\
\hline SCAV-ALL-w & $280 \mathrm{~K}$ & all aerosols mixed & $\begin{array}{l}\text { with activation scavenging, the adapted below-cloud scavenging parameterization } \\
\text { and in-cloud collision scavenging }\end{array}$ \\
\hline $\mathrm{AP}-\mathrm{w}$ & $280 \mathrm{~K}$ & all aerosols mixed & with aerosol processing (including all scavenging processes and aerosol regeneration) \\
\hline CTL-c & $270 \mathrm{~K}$ & $50 \%$ of DU is insoluble & standard simulation \\
\hline SCAV-c & $270 \mathrm{~K}$ & $50 \%$ of DU is insoluble & with aerosol activation and below-cloud scavenging \\
\hline SCAV-ALL-c & $270 \mathrm{~K}$ & $50 \%$ of DU is insoluble & $\begin{array}{l}\text { with activation scavenging, the adapted below-cloud scavenging parameterization } \\
\text { and in-cloud collision scavenging }\end{array}$ \\
\hline AP-c & $270 \mathrm{~K}$ & $50 \%$ of DU is insoluble & with aerosol processing \\
\hline
\end{tabular}

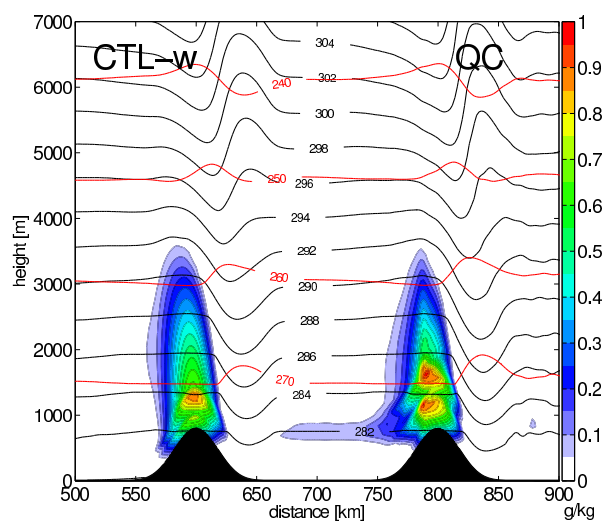

Figure 4. Vertical cross section of the cloud water mixing ratio (QC) for the simulation CTL-w after $10 \mathrm{~h}$. Black lines indicate the potential temperature $(\mathrm{K})$ and red lines the temperature $(\mathrm{K})$. Only part of the computational domain is shown.

duced at the first mountain. In a similar setup, Xue et al. (2010) obtained a maximum cloud water mixing ratio of more than $0.7 \mathrm{~g} \mathrm{~kg}^{-1}$ and a maximum rainwater mixing ratio between $0.01 \mathrm{~g} \mathrm{~kg}^{-1}$ for a dry and $0.12 \mathrm{~g} \mathrm{~kg}^{-1}$ for a wet environment. The generated clouds are almost entirely composed of cloud droplets, producing only a negligible amount of rain. Newly formed raindrops subsequently evaporate within the same time step as no significant amount of precipitation remains in the atmosphere or falls to the surface. The four simulations differ regarding the treatment of aerosol scavenging and regeneration processes which directly impacts the aerosol population. This becomes apparent in the number concentration of internally mixed/soluble aerosol particles larger than $35 \mathrm{~nm} N_{>35 \mathrm{~nm}}$ (Fig. 5), which represents the number concentration of potential CCN in the model. In simulation CTL-w, where aerosol scavenging and regeneration processes are neglected, the aerosol number concentration $N_{>35 \mathrm{~nm}}$ is only affected by the dynamical flow over the mountain leading to a minor variation between 325 and 400 particles per $\mathrm{cm}^{3}$. The impact of activation and belowcloud scavenging becomes apparent in simulation SCAV-w where $N_{>35} \mathrm{~nm}$ is significantly reduced down to 200 particles per $\mathrm{cm}^{3}$ in air masses which have passed through a cloud. Cloud droplet formation and collisions between aerosol particles and sedimenting hydrometeors reaching the surface efficiently scavenge aerosol particles in the region above the mountains. The corresponding air masses are then advected downstream so that reduced aerosol concentrations can be observed in the entire lower part of the model domain downstream of the first mountain. Simulation SCAVALL-w includes in-cloud collision scavenging and a more explicit treatment of below-cloud scavenging, as collisions with all sedimenting hydrometeors and not only with the ones reaching the surface are considered. In this simulation, $N_{>35} \mathrm{~nm}$ shows a similar pattern. In-cloud collisions mainly involve Aitken-mode particles, which only represent a small subset of $N_{>35 \mathrm{~nm}}$. In simulation AP-w, some of the scavenged aerosol particles are replenished by aerosol regeneration upon evaporation in the downdraft region at the downslope side of the mountains. Since the prevailing wind in the simulations is unidirectional, most of the regenerated aerosol particles released upon evaporation in the first cloud are directly advected downstream towards the second mountain where they may impact further cloud formation.

However, before being released upon evaporation, inhydrometeor aerosol particles are subject to aerosol processing within the cloud. The transfer rates for in-hydrometeor aerosol mass illustrate the importance of the different microphysical processes for cloud processing of aerosol mass. The aerosol mass transfer rates after $10 \mathrm{~h}$ of simulation time for the cloud over the first mountain are shown in Fig. 6. Aerosol activation denotes the condensation of water vapor onto aerosol particles leading to the formation of cloud droplets. Aerosol activation and thus cloud droplet formation occur on the upslope side of the mountain between 60 and $20 \mathrm{~km}$ ahead of the mountain crest $(540-580 \mathrm{~km})$ where the cloud starts to form. Other processes which can potentially transfer aerosol mass from the unactivated aerosol modes into the in-hydrometeor modes are in-cloud impaction scavenging and below-cloud scavenging. However, in the present cloud, their contributions to the total in-hydrometeor aerosol 

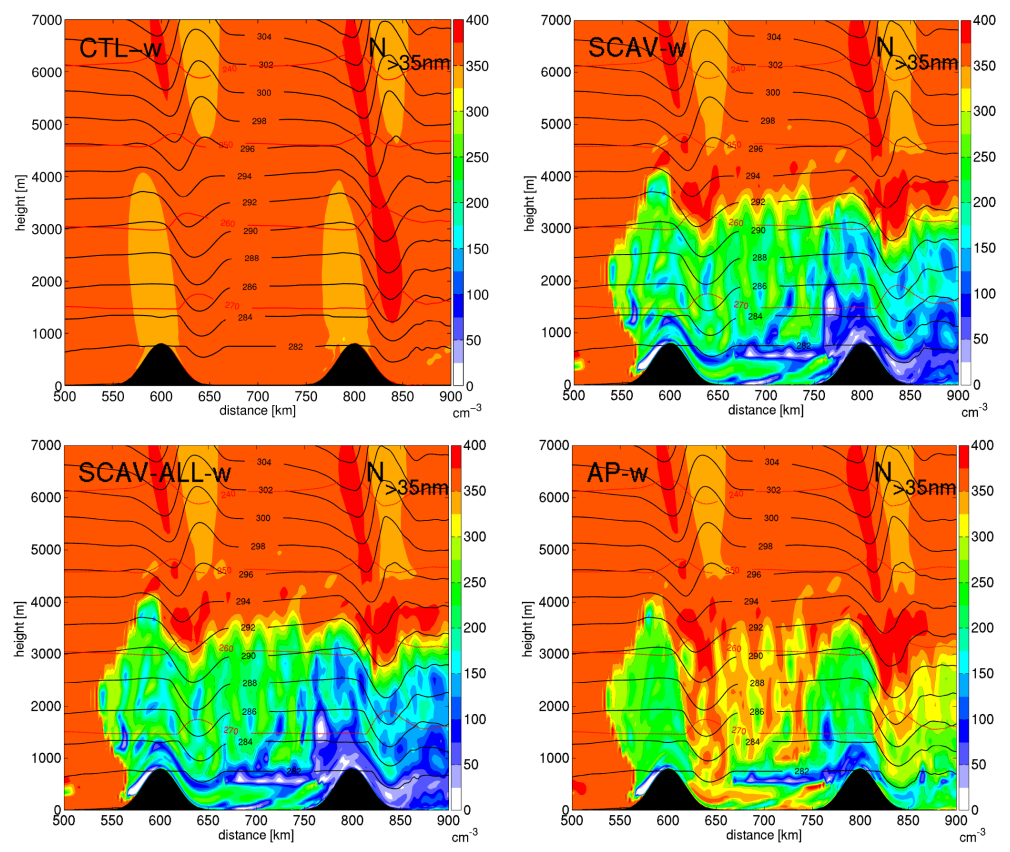

Figure 5. Vertical cross section of the number concentration of aerosol particles larger than $35 \mathrm{~nm}\left(N_{>} 35 \mathrm{~nm}\right)$ which may potentially act as $\mathrm{CCN}$ in the model for simulation CTL-w, SCAV-w, SCAV-ALL-w and AP-w after $10 \mathrm{~h}$. Black lines indicate the potential temperature (K) and red lines the temperature $(\mathrm{K})$. Only part of the computational domain is shown.

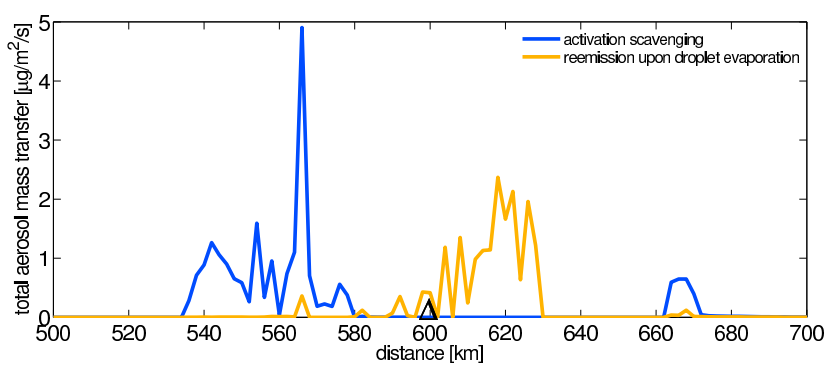

Figure 6. Vertically integrated aerosol mass transfer rates per second of different processes within the microphysical scheme along the flow direction after $10 \mathrm{~h}$ in simulation AP-w over the first mountain (mountain peak represented by the triangle at $600 \mathrm{~km}$ ). Only aerosol mass transfer rates larger than $0.2 \mu \mathrm{g} \mathrm{m}^{-2} \mathrm{~s}^{-1}$ are shown.

mass remain negligible. A large part of in-droplet aerosol mass is released back to the unactivated aerosol modes upon cloud droplet evaporation. Most of the aerosol re-emission occurs behind the mountain crest between 600 and $630 \mathrm{~km}$ on the downslope side of the mountain. The other microphysical processes generate insignificant transfer rates.

The recycled aerosol particles are re-attributed to the free aerosol modes changing the size distribution and total number concentration of the interstitial or unactivated aerosol particles. Figure 7 depicts the vertical profile of $N_{>35} \mathrm{~nm}$ upstream (left panel) and downstream (right panel) of the first cloud. Upstream of the first mountain, the four simulations exhibit the same constant vertical profile of $N_{>35} \mathrm{~nm}$ with an average value of 360 particles per $\mathrm{cm}^{3}$. After passage over the first mountain, the simulations show distinctly different vertical profiles. In simulation CTL-w the almost-constant vertical profile is conserved. The other simulations reveal a reduction in $N_{>35 \mathrm{~nm}}$ from the surface up to an altitude of $3700 \mathrm{~m}$. Simulations SCAV-w and SCAV-ALL-w include an almost-constant reduction to around 220 particles per $\mathrm{cm}^{-3}$ with considerable variations in the lower $1000 \mathrm{~m}$. The strong peak at about $600 \mathrm{~m}$ altitude corresponds to new droplet formation between the two mountains. As the differences between these two simulations remain small, in-cloud scavenging and the adapted below-cloud scavenging parameterization accounting for all aerosol-hydrometeor collisions have only a negligible impact on $N_{>35} \mathrm{~nm}$ in the present setup. In simulation AP-w, the loss in $N_{>35} \mathrm{~nm}$ is partly replenished, maintaining a similar pattern in the vertical profile to the simulations SCAV-w and SCAV-ALL-w.

The total aerosol mass density also shows varying vertical profiles for the different simulations downstream of the first mountain (Fig. 8 right panel). In simulation CTL-w the vertical profile is conserved upstream and downstream of the mountain. Simulations SCAV-w and SCAV-ALL-w reveal similar vertical profiles with a reduction of the total aerosol mass density up to an altitude of $3700 \mathrm{~m}$. The observed variations in the lower $1000 \mathrm{~m}$ due to new cloud formation between the mountains are also reflected in the profiles of the aerosol mass density. Simulation AP-w shows that most of the scavenged aerosol mass is replenished by evaporation throughout the column. In the lowest $1000 \mathrm{~m}$ the verti- 

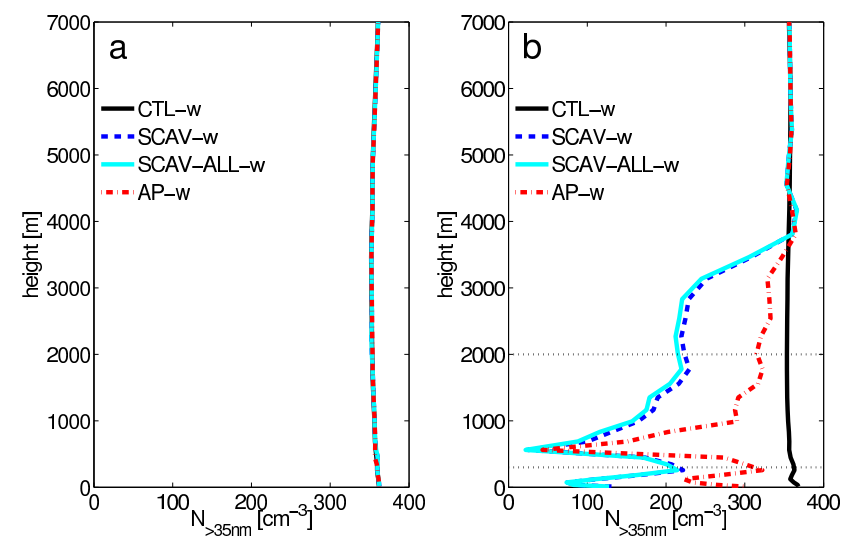

Figure 7. Vertical profile of the number concentration of aerosol particles larger than $35 \mathrm{~nm}\left(N_{>} 35 \mathrm{~nm}\right)$ after $10 \mathrm{~h}$ (a) upstream (averaged between 510 and $530 \mathrm{~km}$ ) and (b) downstream (averaged between 680 and $720 \mathrm{~km}$ ) of the first mountain for the warm cloud cases. Dotted horizontal lines indicate altitudes at which cumulative aerosol size distributions are compiled.

cal profile follows the same pattern as in simulation SCAV-w and SCAV-ALL-w.

The mean cumulative aerosol number and mass concentrations of the Aitken, accumulation and coarse modes downstream of the first orographic cloud at 300 and $2000 \mathrm{~m}$ altitude are depicted in Figs. 9 and 10. The size distributions are calculated from the simulated values for the number concentrations and dry radii of the different aerosol modes. To obtain representative values for the processed air masses after passage over the mountain, the variables are averaged horizontally between 680 and $720 \mathrm{~km}$. We adopt the standard deviation from the initial measurements for the nucleation $(\sigma=2.13)$ and Aitken modes $(\sigma=1.61)$ and the prescribed value in COSMO-Model for the coarse mode $(\sigma=2.0)$. The number size distributions (Figs. 9a and 10a) are characterized by a bimodal shape of Aitken- and accumulation-mode particles. Differences between the initial aerosol number concentration and CTL-w are due to aerosol coagulation and sedimentation processes, as the corresponding air masses have been exposed to aerosol microphysical processes in the model domain for $10 \mathrm{~h}$. After $10 \mathrm{~h}$ the bimodal shape of the aerosol number concentration becomes more pronounced and the number of aerosol particles in both modes is reduced. The aerosol mass distribution is dominated by accumulationmode particles, as Aitken-mode particles are too small to contribute significantly to the total aerosol mass. A slight reduction of the aerosol mass distribution can be observed in CTL-w at $2000 \mathrm{~m}$ altitude (Fig. 10b). In simulation SCAV$\mathrm{w}$ the scavenging processes within the orographic cloud impact the aerosol size distribution by reducing the number and mass of unactivated aerosol particles. Due to activation scavenging, $N_{>35 \mathrm{~nm}}$ is removed from the atmosphere, reducing primarily the accumulation-mode number concentration and shifting the mean size of the Aitken-mode towards
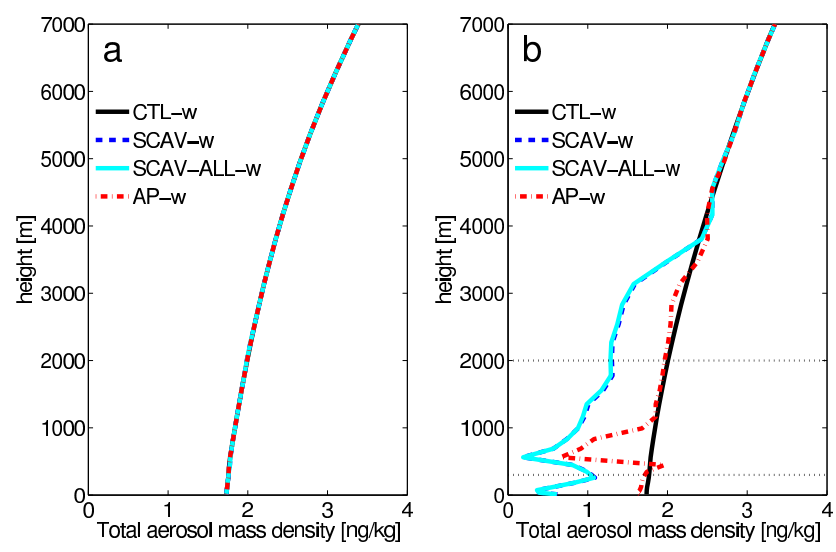

Figure 8. Vertical profile of the total aerosol mass density after $10 \mathrm{~h}$ (a) upstream (averaged between 510 and $530 \mathrm{~km}$ ) and (b) downstream (averaged between 680 and $720 \mathrm{~km}$ ) of the first mountain for the warm cloud cases. Dotted horizontal lines indicate altitudes at which cumulative aerosol size distributions are compiled.

smaller sizes. The two aerosol modes appear clearly separated and the bimodal shape of the aerosol number concentration becomes more distinct. The scavenging processes also cause a decrease in the aerosol mass distribution. In simulation SCAV-ALL-w the adapted parameterizations for belowcloud scavenging and in-cloud collision scavenging between interstitial aerosol particles and cloud droplets induce an additional decrease in Aitken-mode particles compared to simulation SCAV-w. A sensitivity test revealed that this reduction is mainly due to in-cloud collision scavenging. No significant impact on the aerosol mass distribution can be observed as Aitken-mode particles account for only a negligible fraction of the aerosol mass due to their small size. In simulation AP-w, part of the processed aerosol particles is regenerated upon evaporation, increasing the number concentration and mass of aerosol particles compared to SCAV-ALLw. The release of processed aerosol particles significantly increases the number concentration of the Aitken and accumulation modes along with a gain in the aerosol mass distribution compared to SCAV-ALL-w. Regenerated Aitken-mode particles have an increased size and mass compared to the background Aitken-mode particles. Therefore, the average radius of the combined Aitken mode is increased shifting the lognormal size distribution towards larger sizes. The Aitken mode thus appears as a hump on the left-hand side of the accumulation-mode size distribution. At $2000 \mathrm{~m}$ altitude, the aerosol mass distribution reveals the formation of some large coarse-mode particles that impact the aerosol mass distribution, but not the aerosol number concentration.

As aerosol particles act as $\mathrm{CCN}$ for cloud droplet formation, the changes in the aerosol size distributions impact cloud formation at the second mountain. The cloud droplet number concentration in simulation AP-w after $10 \mathrm{~h}$ over the second mountain and the difference in cloud droplet number 

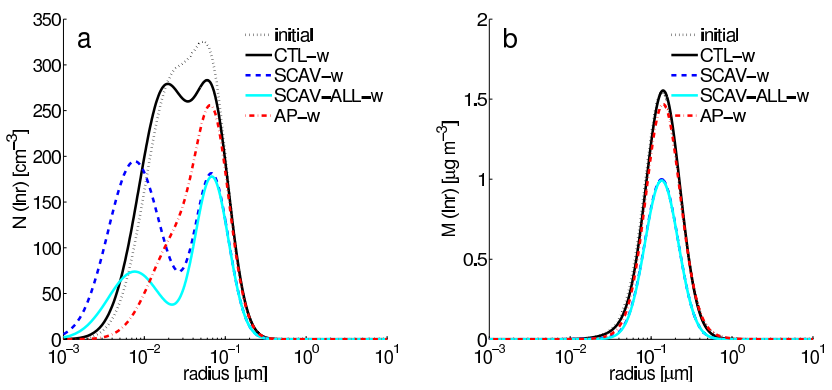

Figure 9. Cumulative aerosol (a) number and (b) mass size distribution after cloud passage after $10 \mathrm{~h}$ for the warm cloud cases. The values are averaged horizontally between 680 and $720 \mathrm{~km}$ at $300 \mathrm{~m}$ altitude.

concentration between simulations AP-w and SCAV-ALL-w are depicted in Fig. 11a and b. In simulation AP-w, significantly more cloud droplets are formed than in SCAV-ALL-w. As the liquid water content of the cloud is only marginally influenced by the modified aerosol concentrations, this translates in a larger number of droplets, which are smaller sized. Changes in the droplet size distribution potentially affect rain formation. However, as the present cloud is characterized as non-precipitating with no measurable rainwater content, a potential reduction of rainwater content and raindrop number concentration cannot be observed.

The difference in cloud droplet number concentrations over the second mountain between simulations AP-w and CTL-w is shown in Fig. 11c. As already seen earlier in this paper, $N_{>35 \mathrm{~nm}}$ is reduced in AP-w compared to CTL-w. This results in a strong diminution of the cloud droplet number concentration. Figure 11d illustrates the difference in cloud droplet number concentrations over the second mountain between simulations AP-w and SCAV-w. The results are similar to Fig. $11 \mathrm{~b}$ where the difference between simulations AP-w and SCAV-ALL-w is shown. Based on similar vertical profiles of $N_{>35 \mathrm{~nm}}$ in simulation SCAV-ALL-w and SCAV$\mathrm{W}$, comparable cloud droplet number concentrations are produced in both simulations. This result illustrates that in-cloud collision scavenging impacts the aerosol size distributions, but has only marginal influence on cloud droplet formation. Obviously, the lowest cloud droplet number concentrations are observed in SCAV-w and SCAV-ALL-w. As no aerosol regeneration is taken into account, all newly formed clouds droplets at the second mountain activated from aerosol particles that have not been activated at the first mountain. Xue et al. (2010) observed a similar relationship between aerosol regeneration and cloud droplet number concentration.

\section{Sensitivity tests}

In order to evaluate the uncertainties of the presented results sensitivity studies are carried out. A first set of simulations is initialized with wintertime aerosol size distributions following Muhlbauer et al. (2010) and Xue et al. $(2010,2012)$
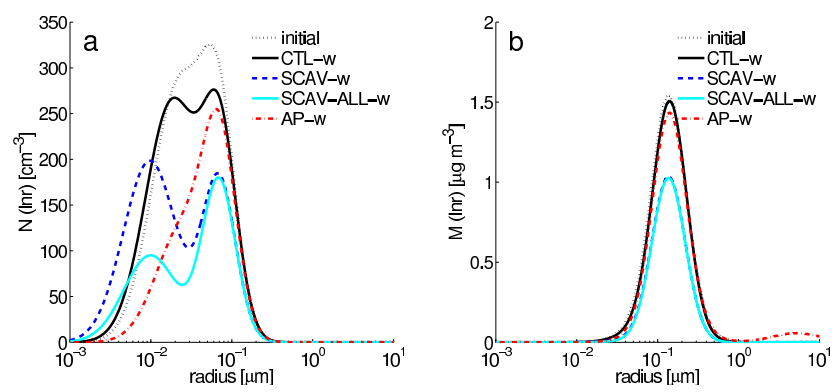

Figure 10. Cumulative aerosol (a) number and (b) mass size distribution after cloud passage after $10 \mathrm{~h}$ for the warm cloud cases. The values are averaged horizontally between 680 and $720 \mathrm{~km}$ at $2000 \mathrm{~m}$ altitude.

which represent a clean aerosol case. Accordingly, the number concentrations of the Aitken and accumulation modes are reduced to 310 and $40 \mathrm{~cm}^{-3}$ respectively. The simulations generate precipitating warm-phase clouds with a maximum cloud liquid water mixing ratio of $0.76 \mathrm{~g} \mathrm{~kg}^{-1}$ and a maximum rainwater mixing ratio of $0.10 \mathrm{~g} \mathrm{~kg}^{-1}$ at the first mountain. As expected, the cloud water content is reduced and the rainwater content is increased in the clean simulations as compared to the more polluted warm case presented before. Aerosol mass transfer rates for the corresponding simulation with aerosol processing are depicted in Fig. 12. In this simulation, the aerosol mass transfer rates which are caused by activation scavenging and aerosol regeneration upon cloud droplet evaporation prevail. Aerosol mass transfer into raindrops caused by collisions and autoconversion, and the subsequent removal through precipitation or regeneration through evaporating raindrops play a minor role. In a cloud with enhanced rainwater content, these rates might increase. The cumulative aerosol number and mass size distributions for the different clean case simulations averaged between 680 and $720 \mathrm{~km}$ at an altitude of $300 \mathrm{~m}$ are displayed in Fig. 13. Aerosol scavenging in simulation SCAV and SCAVALL reduces the number of aerosol particles in the Aitken and accumulation mode, and it shifts the Aitken mode towards smaller radii. The impact of aerosol regeneration can be identified as a small increase in the number concentrations of both aerosol modes and a shift of the Aitken mode towards larger radii. These findings agree with the results of the polluted warm case.

In the employed model configuration, the standard deviations of the log-normal aerosol size distributions are based on observations ( $\sigma=1.59$ for the nucleation, $\sigma=2.13$ for the Aitken, $\sigma=1.61$ for the accumulation, and $\sigma=2.0$ for the coarse mode). To investigate the dependence of the results on the standard deviation, we conducted a set of simulations employing the M7 standard deviations which are 1.59 for the nucleation, Aitken and accumulation and 2.0 for the coarse mode. The standard deviations have fixed values in the 

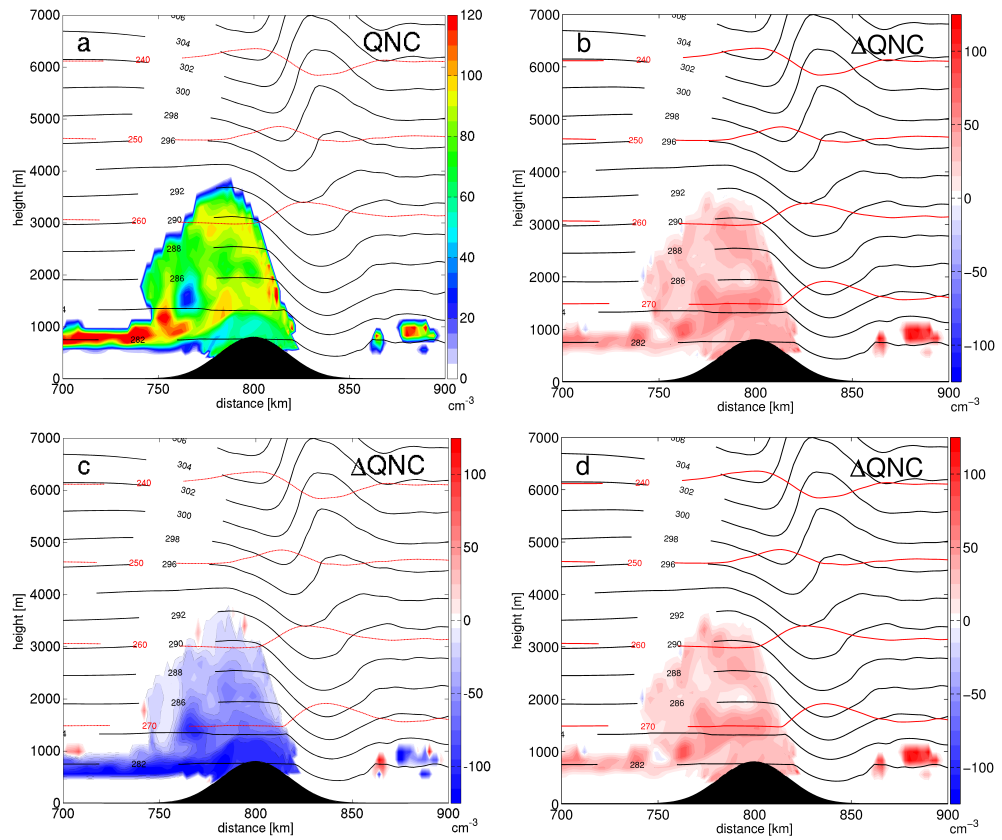

Figure 11. Number concentration of cloud droplets in (a) simulation AP-w and difference in cloud droplet number concentration between simulations (b) AP-w and SCAV-ALL-w, (c) AP-w and CTL-w and (d) AP-w and SCAV-w after 10 h over the second mountain. Black lines indicate the potential temperature $(\mathrm{K})$ and red lines the temperature $(\mathrm{K})$. Only part of the computational domain is shown.

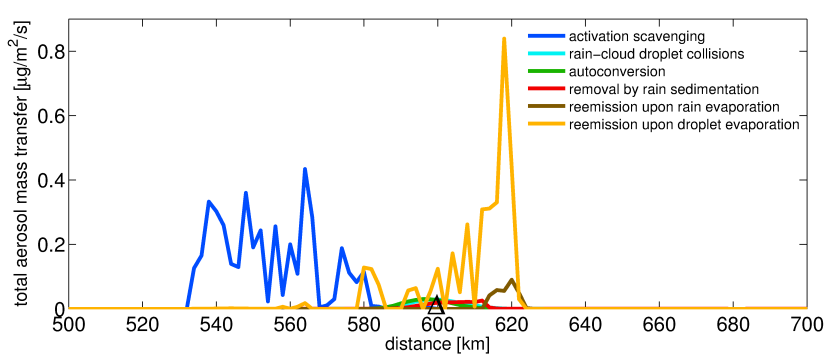

Figure 12. Vertically integrated aerosol mass transfer rates per second of different processes within the microphysical scheme along the flow direction after $10 \mathrm{~h}$ in the simulation with aerosol processing for the clean aerosol initialization over the first mountain (mountain peak represented by the triangle at $600 \mathrm{~km}$ ). Only aerosol mass transfer rates larger than $0.02 \mu \mathrm{g} \mathrm{m}^{-2} \mathrm{~s}^{-1}$ are shown.

model. Further sensitivity experiments include simulations with a reduced surface relative humidity of 85 and $80 \%$.

In order to evaluate the impact of aerosol processing and regeneration on the aerosol population and on the number concentration of possible $\mathrm{CCN}$ in the model, the aerosol population in a sample domain downstream of the first mountain between 680 and $720 \mathrm{~km}$ is analyzed. The results at 300 and $2000 \mathrm{~m}$ altitude are summarized in Table $5 . N_{\text {reg }}$ denotes the difference in the total aerosol particles number concentration averaged over the sample area between simulations AP and SCAV-ALL and thus represents the additional particles due to aerosol processing and regeneration. This number concen- tration is compared to the total aerosol number concentration $N_{\text {total }}$ (Aitken, accumulation and coarse mode) in the sample area in simulation AP. A similar approach is applied for CCN by comparing the difference in the $\mathrm{CCN}$ number concentration between simulation AP and SCAV-ALL $\left(N_{\text {reg }}^{\mathrm{CCN}}\right)$ to the $\mathrm{CCN}$ number concentration in simulation $\mathrm{AP}\left(N_{\text {total }}^{\mathrm{CCN}}\right)$. In the aerosol polluted experiments, regenerated aerosol particles account for $23-39 \%$ of the total aerosol particles and for $33-47 \%$ of the CCN particles at $300 \mathrm{~m}$ altitude. Their contributions are slightly reduced to $18-23 \%$ of the total aerosol particles and to $32-30 \%$ of the possible CCN at $2000 \mathrm{~m}$ altitude. In the two clean cases, regenerated particles represent less than $10 \%$ of the total aerosol particles. However, they account for 35-46\% of the CCN particles. In the clean experiments, the aerosol population is mainly composed of Aitken-mode particles as can be seen in Fig. 13.

In order to evaluate how many of the scavenged aerosol particles are recycled by the cloud, the difference of the aerosol concentrations between simulation SCAV-ALL and CTL ( $\left.N_{\text {scav }}\right)$ is calculated. $N_{\text {scav }}$ represents the missing particles due to scavenging processes. The relationship between $N_{\text {reg }}$ and $N_{\text {scav }}$ thus shows how many of the missing particles due to scavenging are replenished by regenerated particles. In the polluted experiments, this proportion ranges between 24 and $39 \%$ representing about one-quarter to one-third of the missing aerosol particles due to scavenging. In the clean experiments, it does not exceed $27 \%$. These findings are lower than in the study of Xue et al. (2010), who found that regener- 


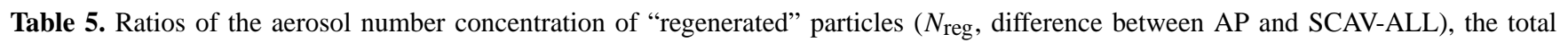
aerosol number concentration in simulation AP $\left(N_{\text {total }}\right)$, the number concentration of "regenerated" particles potentially acting as CCN $\left(N_{\text {reg }}^{\mathrm{CCN}}\right.$, difference between AP and SCAV-ALL), the number concentration of CCN in simulation $\mathrm{AP}\left(N_{\text {total }}^{\mathrm{CCN}}\right)$ and the number concentration of "missing particles due to scavenging" ( $N_{\text {scav }}$, difference between SCAV-ALL and CTL) of the sensitivity studies of the warm case. The values are averaged horizontally between 680 and $720 \mathrm{~km}$ at 300 and $2000 \mathrm{~m}$ altitude. $\sigma^{*}$ denotes the simulations with the M7 standard deviations. The first two lines describe the analyzed warm case.

\begin{tabular}{llllll}
\hline $\mathrm{RH}_{\text {surface }}$ & Altitude & Aerosol initialization & $N_{\text {reg }} / N_{\text {total }}$ & $N_{\text {reg }}^{\mathrm{CCN}} / N_{\text {total }}^{\mathrm{CCN}}$ & $N_{\text {reg }} / N_{\text {scav }}$ \\
\hline $90 \%$ & $300 \mathrm{~m}$ & polluted summer & 0.23 & 0.33 & 0.24 \\
& $2000 \mathrm{~m}$ & polluted summer & 0.18 & 0.32 & 0.24 \\
$85 \%$ & $300 \mathrm{~m}$ & polluted summer & 0.39 & 0.47 & 0.36 \\
& $2000 \mathrm{~m}$ & polluted summer & 0.18 & 0.35 & 0.25 \\
$80 \%$ & $300 \mathrm{~m}$ & polluted summer & 0.31 & 0.43 & 0.26 \\
& $2000 \mathrm{~m}$ & polluted summer & 0.23 & 0.39 & 0.39 \\
$90 \%, \sigma^{*}$ & $300 \mathrm{~m}$ & polluted summer & 0.23 & 0.33 & 0.24 \\
$90 \%$ & $2000 \mathrm{~m}$ & polluted summer & 0.18 & 0.32 & 0.24 \\
& $300 \mathrm{~m}$ & clean winter & 0.04 & 0.35 & 0.12 \\
$80 \%$ & $2000 \mathrm{~m}$ & clean winter & 0.08 & 0.44 & 0.27 \\
& $300 \mathrm{~m}$ & clean winter & 0.05 & 0.46 & 0.19 \\
& $2000 \mathrm{~m}$ & clean winter & 0.03 & 0.38 & 0.12 \\
\hline
\end{tabular}
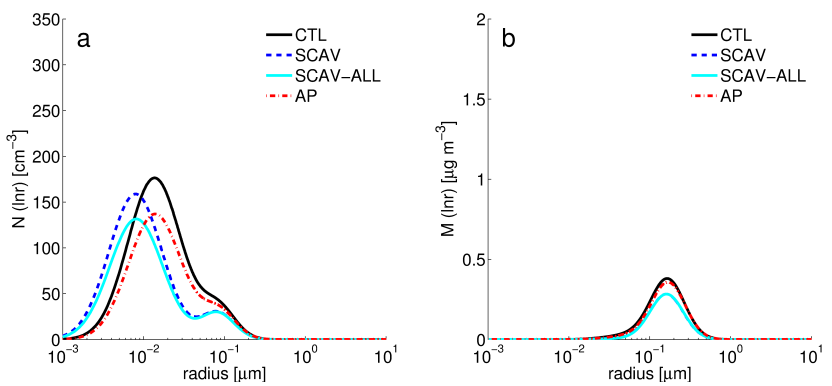

Figure 13. Cumulative aerosol (a) number and (b) mass size distribution after cloud passage after $10 \mathrm{~h}$ for the warm simulations with clean aerosol initialization. The values are averaged horizontally between 680 and $720 \mathrm{~km}$ at $300 \mathrm{~m}$ altitude.

ated particles replenish one-third to two-thirds of the missing particles.

The presented sensitivity experiments show that the impact of regenerated aerosol particles on the aerosol and $\mathrm{CCN}$ number concentrations depends on the cloud regime and the aerosol population. Variations in the relative humidity and the standard deviation are shown to have a smaller influence.

\subsection{Mixed-phase cloud}

We employ the cold temperature profile with a surface temperature of $270 \mathrm{~K}$ to generate mixed-phase orographic clouds over the two mountains. The ascent over the bell-shaped mountains results in the formation of liquid cloud droplets on the upslope side of the mountain. After $10 \mathrm{~h}$, liquid droplets only persist at cloud base (Fig. 14). Advected aloft, they may undergo heterogeneous freezing processes to form ice crystals which constitute the upper part of the cloud. Due to the difference in saturation vapor pressure over ice and over liquid, cloud droplets may also evaporate in the presence of ice crystals allowing for the enhanced condensation of water vapor on preexisting ice crystals (Wegener-BergeronFindeisen process). The cloud over the first mountain consists mainly of cloud ice and snow with little cloud liquid water. In this first cloud, collision processes between ice crystals lead to the aggregation of snowflakes which sediment to the surface. A large part of the cloud water is removed from the atmosphere by sedimenting snow, reducing the available water vapor in the atmosphere. Therefore, the environment downstream of the first cloud is drier than in front of the first cloud. The cloud over the second mountain developing in this drier environment has much less cloud ice and the snow formation processes are suppressed.

In mixed-phase clouds, a multitude of microphysical processes can take place which affect the aerosol population. In the present setup, the in-hydrometeor aerosol mass is concentrated in cloud droplets and snow, whereas the aerosol mass within ice crystals appears to be negligible. Figure 15 illustrates which processes are important in terms of the transfer of aerosol mass into, out of and between the different hydrometeors. Aerosol mass is transferred into cloud droplets mostly by activation scavenging. When the cloud droplets reach higher altitudes some ice is formed heterogeneously via condensation/immersion freezing or contact freezing. Although these processes are essential for the formation of ice crystals in the model, their influence on the aerosol transfer remains negligible. In the presence of ice crystals, the liquid droplets rapidly evaporate and the water vapor condenses on the ice phase (Wegener-BergeronFindeisen process) when the vapor pressure is below water saturation. Therefore, cloud droplet activation and evapora- 

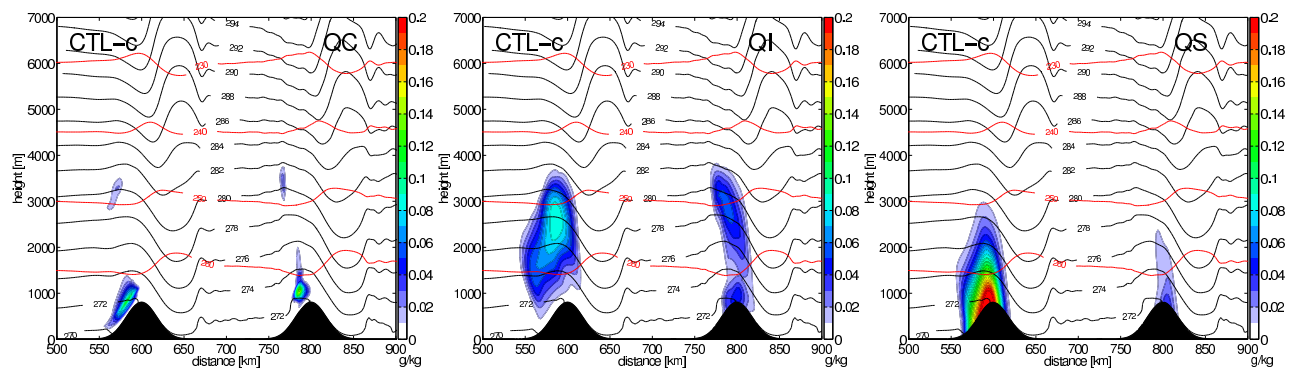

Figure 14. Vertical cross section of the cloud water mixing ratio (QC), ice water mixing ratio (QI) and snow water mixing ratio (QS) in simulation CTL-c after $10 \mathrm{~h}$. Black lines indicate the potential temperature $(\mathrm{K})$ and red lines the temperature $(\mathrm{K})$. Only part of the computational domain is shown.

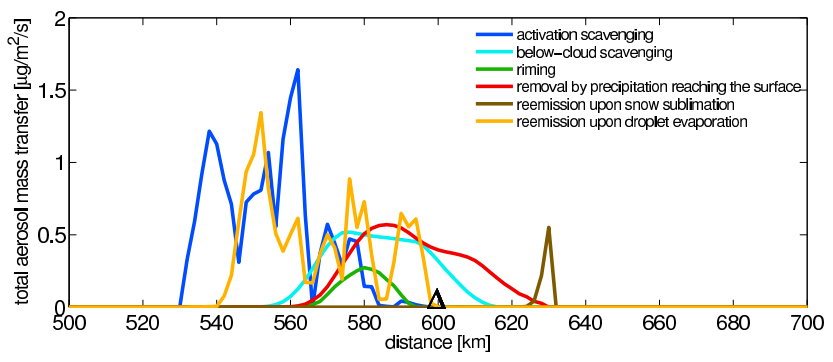

Figure 15. Vertically integrated aerosol mass transfer rates of different processes within the microphysical scheme along the flow direction after $10 \mathrm{~h}$ in simulation AP-c over the first mountain (mountain peak represented by the triangle at $600 \mathrm{~km}$ ). Only part is of computational domain is shown. Only aerosol mass transfer rates larger than $0.2 \mu \mathrm{g} \mathrm{m}^{-2} \mathrm{~s}^{-1}$ are shown.

tion take place at the same horizontal location but at different altitudes. These two processes form a first aerosol processing cycle which acts via the liquid phase. The ice crystals grow and aggregate to form snowflakes which efficiently take up aerosol mass by riming with cloud droplets and belowcloud scavenging of interstitial aerosol particles. Sedimenting snowflakes remove aerosol mass from the atmosphere. Downstream of the cloud, some snowflakes sublimate releasing aerosol mass back to the interstitial mode (peak at $630 \mathrm{~km}$ ). The second aerosol processing cycle therefore covers the interactions with snowflakes. A connection between the two cycles represents the riming process which transfers aerosol mass from cloud droplets to snowflakes. The other microphysical processes within the model are negligible for the transfer of aerosol mass in the present case study.

The described processes within the first cloud have an important influence on the vertical distribution of aerosol particles. Figure 16 shows the vertical profile of the total aerosol mass for the different simulations upstream (left panel) and downstream (right panel) of the first cloud. All simulations show the same vertical profile upstream of the first mountain. In simulation CTL-c, the vertical profile remains constant after passage over the mountain. Simulation SCAV-c includes a reduction of aerosol mass in the lower $3700 \mathrm{~m}$ where the cloud forms. This reduction is due to activation and below-cloud scavenging. The modified scavenging parameterizations in simulation SCAV-ALL-c generate a significantly larger diminution of the aerosol mass concentration in the lower part of the atmosphere. In simulation SCAV-ALLc, below-cloud scavenging is treated differently, as all aerosol particles colliding with sedimenting rain or snow are removed from the unactivated aerosol modes, whereas in simulation SCAV-c only the fraction corresponding to the fraction of precipitation reaching the surface is removed. Therefore, below-cloud scavenging is far more efficient in simulation SCAV-ALL-c, as apparent in the amplified reduction of the vertical profile below $2000 \mathrm{~m}$ altitude. Additionally, SCAVALL-c accounts for in-cloud collision scavenging and scavenging of aerosol particles acting as contact IN. In simulation AP-c, evaporation processes lead to the release of additional aerosol particles, increasing the aerosol mass compared to SCAV-ALL-c. Above about $2200 \mathrm{~m}$ almost all of the scavenged aerosol mass is replenished by aerosol regeneration upon evaporation.

The cumulative aerosol number and mass size distributions of the Aitken, accumulation and coarse modes downstream of the first mountain at 300 and $2000 \mathrm{~m}$ altitude are depicted in Figs. 17 and 18. The values are averaged horizontally between 680 and $720 \mathrm{~km}$. Aerosol microphysical processes like coagulation and sedimentation lead to a reduction in the aerosol number and mass size distribution after $10 \mathrm{~h}$ in simulation CTL-c compared to the initial aerosol size distributions. At both altitudes the bimodal shape of the aerosol number size distribution becomes more distinct while both Aitken and accumulation modes are reduced. The aerosol mass size distribution determined by the accumulation mode is slightly reduced due to sedimentation. Scavenging processes in simulation SCAV-c lead to a considerable reduction in aerosol number and mass. The influence on the shape of the aerosol number size distribution becomes particularly apparent at $300 \mathrm{~m}$ altitude, where Aitken and accumulation modes are clearly separated by a large gap. At this low altitude, the aerosol mass size distribution is significantly reduced. The reduction in aerosol mass and num- 
Table 6. Ratios of the aerosol number concentration of "regenerated" particles ( $N_{\text {reg, }}$ difference between AP and SCAV-ALL), the total aerosol number concentration in simulation AP $\left(N_{\text {total }}\right)$, the number concentration of "regenerated" particles potentially acting as CCN $\left(N_{\text {reg }}^{\mathrm{CCN}}\right.$, difference between AP and SCAV-ALL), the number concentration of CCN in simulation $\mathrm{AP}\left(N_{\text {total }}^{\mathrm{CCN}}\right)$ and the number concentration of "missing particles due to scavenging" ( $N_{\text {Scav }}$, difference between SCAV-ALL and CTL) of the sensitivity studies of the cold case. The values are averaged horizontally between 680 and $720 \mathrm{~km}$ at 300 and $2000 \mathrm{~m}$ altitude. $\sigma^{*}$ denotes the simulations with the M7 standard deviations. The first two lines describe the analyzed cold case.

\begin{tabular}{llllll}
\hline $\mathrm{RH}_{\text {surface }}$ & Altitude & Aerosol initialization & $N_{\text {reg }} / N_{\text {total }}$ & $N_{\text {reg }}^{\mathrm{CCN}} / N_{\text {total }}^{\mathrm{CCN}}$ & $N_{\text {reg }} / N_{\text {scav }}$ \\
\hline $90 \%$ & $300 \mathrm{~m}$ & polluted summer & 0.21 & 0.57 & 0.04 \\
& $2000 \mathrm{~m}$ & polluted summer & 0.18 & 0.38 & 0.36 \\
$85 \%$ & $300 \mathrm{~m}$ & polluted summer & 0.17 & 0.36 & 0.04 \\
& $2000 \mathrm{~m}$ & polluted summer & 0.24 & 0.48 & 0.49 \\
$80 \%$ & $300 \mathrm{~m}$ & polluted summer & 0.19 & 0.47 & 0.07 \\
& $2000 \mathrm{~m}$ & polluted summer & 0.28 & 0.49 & 0.57 \\
$90 \%, \sigma^{*}$ & $300 \mathrm{~m}$ & polluted summer & 0.21 & 0.57 & 0.04 \\
\multirow{2}{*}{$90 \%$} & $2000 \mathrm{~m}$ & polluted summer & 0.18 & 0.38 & 0.36 \\
& $300 \mathrm{~m}$ & clean winter & 0.03 & 0.55 & 0.03 \\
$80 \%$ & $2000 \mathrm{~m}$ & clean winter & 0.02 & 0.31 & 0.09 \\
& $300 \mathrm{~m}$ & clean winter & 0.01 & 0.26 & 0.05 \\
& $2000 \mathrm{~m}$ & clean winter & 0.05 & 0.43 & 0.27 \\
\hline
\end{tabular}
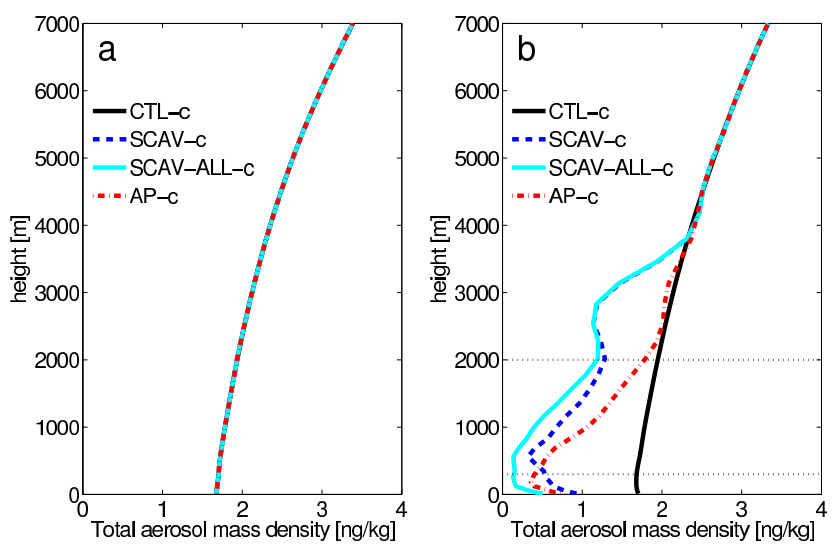

Figure 16. Vertical profile of the total aerosol mass density after $10 \mathrm{~h}$ (a) upstream (averaged between 510 and $530 \mathrm{~km}$ ) and (b) downstream (averaged between 680 and $720 \mathrm{~km}$ ) of the first mountain for the cold cloud cases. Dotted horizontal lines indicate altitudes at which cumulative aerosol size distributions are compiled.

ber at $300 \mathrm{~m}$ altitude is even more pronounced in simulation SCAV-ALL-c where the modified below-cloud scavenging parameterization, in-cloud collision scavenging and scavenging of contact IN remove the major part of unactivated aerosol particles from the atmosphere. A comparison with the non-precipitating warm-phase cloud suggests that an important part of the scavenging is due to the more detailed below-cloud scavenging by sedimenting snow particles. At an altitude of $2000 \mathrm{~m}$, below-cloud scavenging and activation scavenging become less important. The differences between AP and SCAV-ALL illustrate the impact of regenerated aerosol particles on the background aerosol
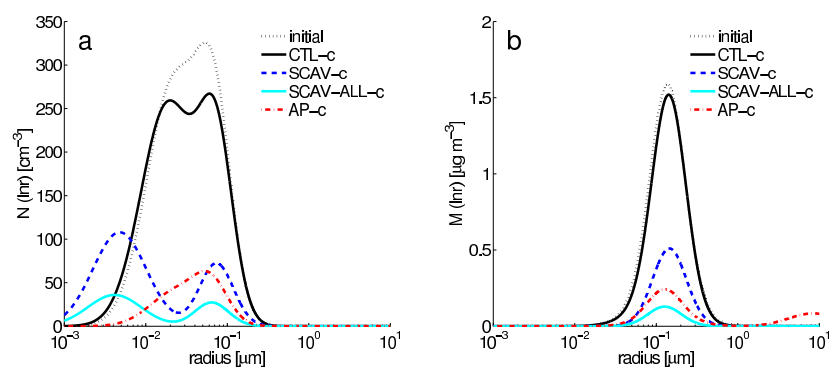

Figure 17. Cumulative aerosol (a) number and (b) mass size distribution after cloud passage after $10 \mathrm{~h}$ for the cold cloud cases. The values are averaged horizontally between 680 and $720 \mathrm{~km}$ at $300 \mathrm{~m}$ altitude.
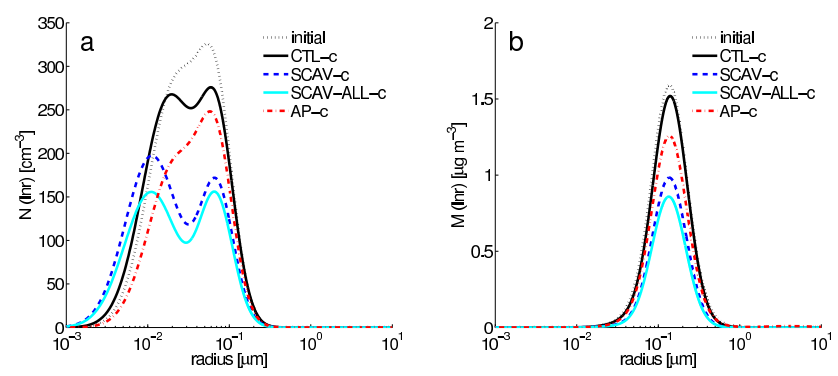

Figure 18. Cumulative aerosol (a) number and (b) mass size distribution after cloud passage after $10 \mathrm{~h}$ for the cold cloud cases. The values are averaged horizontally between 680 and $720 \mathrm{~km}$ at $2000 \mathrm{~m}$ altitude.

size distributions. Aerosol regeneration upon droplet evaporation and snow sublimation in simulation AP-c leads to an increase in aerosol number and mass compared to simulation SCAV-ALL-c. The aerosol number size distribution reveals 

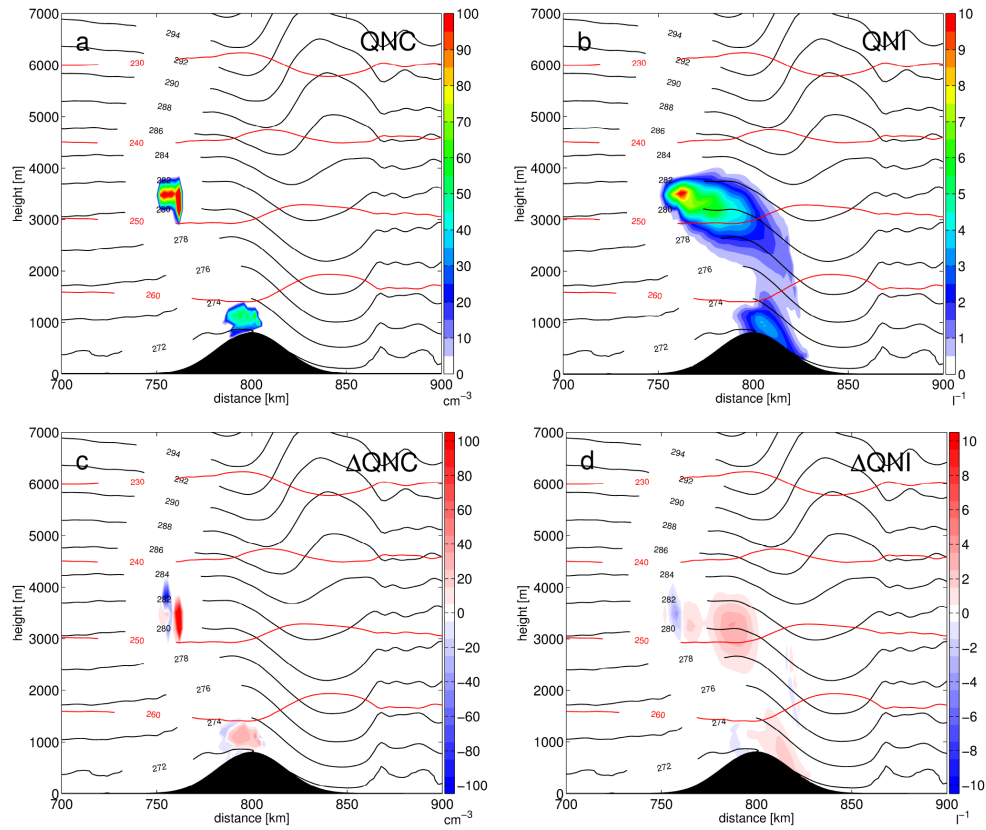

Figure 19. Number concentration of (a) cloud droplets and (b) ice crystals in simulation AP-c and difference between simulation AP-c and SCAV-ALL-c in (c) cloud droplet number concentration and (d) ice crystal number concentration after $10 \mathrm{~h}$ over the second mountain. Black lines indicate the potential temperature $(\mathrm{K})$ and red lines the temperature $(\mathrm{K})$. Only part of the computational domain is shown.

that large Aitken- and accumulation-mode particles are released to the atmosphere. Newly formed Aitken-mode particles have an increased size and mass as compared to the background Aitken-mode particles. The log-normal distribution of the Aitken mode is shifted towards larger size and appears as a bump on the left-hand side of the accumulationmode size distribution. At $300 \mathrm{~m}$ altitude few coarse-mode particles are formed which appear in the aerosol mass distribution.

As aerosol particles serve as $\mathrm{CCN}$ and/or IN, changes in the aerosol number and mass size distribution may impact the number concentration of cloud droplets and ice crystals as shown in Fig. 19. The cloud droplet number and ice crystal number concentrations over the second mountain in simulation AP-c are displayed in Fig. 19a and b, differences between simulations AP-c and SCAV-ALL-c are shown in Fig. 19c and d. The released aerosol particles in AP-c lead to an increase in cloud droplet number concentration as compared to SCAV-ALL-c. The ice crystal number concentration reveals a comparable increase as more cloud droplets and also more aerosol particles are available for heterogeneous freezing processes. However, these changes in the number concentrations do not impact the cloud liquid and ice water content noticeably.

\section{Sensitivity tests}

Several sensitivity test were carried out in order to evaluate the uncertainties of the results. We conducted simulations with a lowered surface relative humidity to 85 and $80 \%$, with altered standard deviations, and with a clean (winter) aerosol initialization. The analysis focuses on the averaged aerosol population downstream of the first mountain between 680 and $720 \mathrm{~km}$. The results at an altitude of 300 and $2000 \mathrm{~m}$ are summarized in Table 6 . The difference between simulations AP and SCAV-ALL $\left(N_{\text {reg }}\right)$ is compared to the total aerosol number concentration of the Aitken, accumulation and coarse modes $\left(N_{\text {total }}\right)$ in simulation AP. Analogously, the difference in the $\mathrm{CCN}$ number concentration between simulation AP and SCAV-ALL $\left(N_{\text {reg }}^{\mathrm{CCN}}\right)$ is related to the CCN number concentration $\left(N_{\text {total }}^{\mathrm{CCN}}\right)$ in simulation AP. Regenerated aerosol particles constitute between 18 and $28 \%$ of the total aerosol particles and between 38 and $57 \%$ of the CCN particles in polluted simulations. Similar to the warm case, the clean sensitivity experiments of the cold case reveal a negligible contribution of regenerated particles to the total aerosol concentration $(<5 \%)$, but constitute a considerably part of the CCN number concentration (26-55\%). Further, we investigate how many of the missing particles due to scavenging are replenished by regenerated particles. $N_{\text {reg }}$ is compared to the difference of the aerosol concentrations between simulation SCAV-ALL and CTL $\left(N_{\text {scav }}\right)$. In all sensitivity experiments at $300 \mathrm{~m}$ altitude, regenerated particles replenish only less than $10 \%$ of the missing particles, supporting the assumption that most of the scavenged particles are removed from the atmosphere by precipitation. At $2000 \mathrm{~m}$ altitude, a replenishment of up to $57 \%$ can be observed. 
The results show that the cloud and the aerosol regime play an important role for aerosol regeneration and its impact on the background aerosol population. For precipitating clouds, the analyzed altitude is a determining factor.

\section{Summary and conclusions}

The effects of warm-phase and mixed-phase orographic clouds on the aerosol population have been evaluated by simulating orographic cloud formation over a 2-D double-bellshaped topography with the regional weather forecast and climate model COSMO-Model. An explicit treatment of inhydrometeor aerosol mass allowing for the consideration of aerosol processing in clouds has been implemented in the model. Aerosol scavenging processes and aerosol processing in clouds including aerosol regeneration upon evaporation or sublimation affect the aerosol population greatly. In this paper, different aerosol cycles have been identified. In the simulated non-precipitating warm-phase cloud, aerosol mass is incorporated in cloud droplets by activation scavenging and released back to the atmosphere upon cloud droplet evaporation. In the simulated precipitating mixed-phase cloud, a significant amount of aerosol mass can be found in cloud droplets and snowflakes, but less in ice crystals. Activation and below-cloud scavenging efficiently transfer aerosol mass into the cloud droplets and snowflakes, while ice crystals are formed heterogeneously from a few cloud droplets allowing for only a limited transfer of aerosol mass. In the mixedphase clouds, two aerosol cycles were identified. A first cycle includes activation scavenging and cloud droplet evaporation due to the WBF process. A second cycle includes the interactions with snowflakes and is connected to the first cycle via the riming process which transfers aerosol from cloud droplets to snowflakes. As aerosol particles are transported together with the sedimenting hydrometeors, a vertical redistribution of the aerosol number and mass concentration occurs with aerosol mass being transported towards lower altitudes or even being removed from the atmosphere. Precipitating snow in the lower atmosphere very efficiently removes aerosol number and mass from the atmosphere.

The present study shows that the different scavenging parameterizations and the consideration of aerosol regeneration modify the total aerosol number and mass and also the shape of the aerosol size distributions. Accounting for aerosol processing in clouds, the scavenged aerosol particles are partly replenished by the release of aerosol particles upon hydrometeor evaporation/sublimation. The released aerosol particles mainly add to the Aitken and accumulation mode. Depending on the simulated cloud, the formation of coarsemode aerosol particles can be observed at specific altitudes. The newly generated large coarse-mode particles are possible candidates for giant cloud condensation nuclei (GCCN) which may lead to rapid rain formation in warm-phase clouds (Saleeby et al., 2009; Posselt and Lohmann, 2008). This in turn would impact the precipitation rate and the longevity of the cloud. However, the current model does not include any specific treatment of GCCN which would allow one to study the impact of these particles in more detail. The release of internally mixed aerosol particles in the accumulation and coarse modes increases the number concentration of possible $\mathrm{CCN}$ in the model impacting further cloud formation. The simulations show that aerosol regeneration increases the cloud droplet number concentration at the second mountain with possible implications for the ice crystal number concentration. In comparison to the standard model version, the aerosol activation and below-cloud scavenging processes revealed to be most important reducing the aerosol number concentration and in turn the cloud droplet number concentration at the second mountain. An influence on the ice crystal number concentration is observable via the changes in cloud droplet number concentration. In-cloud collision scavenging mainly affects the Aitken mode without any important implications for cloud droplet formation in warm-phase clouds. Due to collision processes, insoluble aerosol particles, which potentially may act as ice nuclei in the contact mode, are removed from the free atmosphere limiting the efficiency of contact freezing. However, in the present mixedphase clouds this effect remains negligible.

Changes in the cloud droplet and ice crystal number concentration potentially affect the formation of precipitation in the model. However, in the present setup of non-precipitating warm-phase clouds, the increase in cloud droplet number concentration does not imply any important changes for the rain formation over the second mountain. In a precipitating cloud however, the formation of a greater number but smaller-sized cloud droplets may impede rain formation, as autoconversion and collision efficiencies may be reduced. The influence of the variations in cloud droplet and ice crystal number concentration on the ice water content in the simulated mixed-phase clouds remains negligible. Most of the ice is formed via the Wegener-Bergeron-Findeisen process which effectively adds water vapor to the ice crystals. Due to the high efficiency of this process in the present setup, the number of preexisting ice particles appears to be non-relevant for the total ice water content.

The present study focuses on the influence of aerosol processing in warm-phase and mixed-phase clouds on the aerosol population over two idealized 2-D bell-shaped mountains. A subsequent study should investigate the implications of the modified aerosol spectrum on further cloud formation in a 3-D regional study. Special emphasis should be placed on precipitation formation and the governing cloud microphysical processes.

Acknowledgements. We thank the reviewers for valuable comments and suggestions. The Swiss National Supercomputing Center (CSCS) provided computing resources for our simulations. We thank the Consortium for Small-scale Modeling (COSMO) for code access, the German weather service (DWD) and MeteoSwiss for 
code maintenance, and the Center for Climate Systems Modeling (C2SM) for source code support. We thank Dani Lüthi for technical support.

Edited by: C. Hoose

\section{References}

Albrecht, B. A.: Aerosols, cloud microphysics, and fractional cloudiness, Science, 245, 1227-1230, doi:10.1126/science.245.4923.1227, 1989.

Bergeron, T.: On the physics of clouds and precipitation, in: Proceedings of the 5th Assembly U.G.G.I., Lisbon, 17-24 September 1933, 2, 156-180, 1935.

Bott, A.: A positive definite advection scheme obtained by nonlinear renormalization of the advective fluxes, Mon. Weather Rev., 117, 1006-1016, doi:10.1175/15200493(1989)117<1006:APDASO>2.0.CO;2, 1989.

Boucher, O., Randall, D., Artaxo, P., Bretherton, C., Feingold, G., Forster, P., Kerminen, V.-M., Kondo, Y., Liao, H., Lohmann, U., Rasch, P., Satheesh, S., Sherwood, S., Stevens, B., and Zhang, X.: Clouds and aerosols, in: Climate Change 2013: The Physical Science Basis. Contribution of Working Group I to the Fifth Assessment Report of the Intergovernmental Panel on Climate Change, Cambridge University Press, Cambridge, UK and New York, NY, USA, available at: http://www.ipcc.ch/ipccreports/ar4-wg1.htm (last access: 15 July 2014), 571-657, 2013.

Chou, C., Stetzer, O., Weingartner, E., Jurányi, Z., Kanji, Z. A., and Lohmann, U.: Ice nuclei properties within a Saharan dust event at the Jungfraujoch in the Swiss Alps, Atmos. Chem. Phys., 11, 4725-4738, doi:10.5194/acp-11-4725-2011, 2011.

Clark, T. L. and Farley, R. D.: Severe downslope windstorm calculations in two and three spatial dimensions using anelastic interactive grid nesting: a possible mechanism for gustiness, J. Atmos. Sci., 41, 329-350, doi:10.1175/15200469(1984)041<0329:SDWCIT>2.0.CO;2, 1984.

Cotton, W. R., Tripoli, G. J., Rauber, R. M., and Mulvihill, E. A.: Numerical simulation of the effects of varying ice crystal nucleation rates and aggregation processes on orographic snowfall, J. Clim. Appl. Meteorol., 25, 1658-1680, doi:10.1175/15200450(1986)025<1658:NSOTEO>2.0.CO;2, 1986.

Cozic, J., Verheggen, B., Weingartner, E., Crosier, J., Bower, K. N., Flynn, M., Coe, H., Henning, S., Steinbacher, M., Henne, S., Collaud Coen, M., Petzold, A., and Baltensperger, U.: Chemical composition of free tropospheric aerosol for $\mathrm{PM}_{1}$ and coarse mode at the high alpine site Jungfraujoch, Atmos. Chem. Phys., 8, 407-423, doi:10.5194/acp-8-407-2008, 2008.

Croft, B., Lohmann, U., Martin, R. V., Stier, P., Wurzler, S., Feichter, J., Posselt, R., and Ferrachat, S.: Aerosol size-dependent below-cloud scavenging by rain and snow in the ECHAM5HAM, Atmos. Chem. Phys., 9, 4653-4675, doi:10.5194/acp-94653-2009, 2009.

Diehl, K. and Wurzler, S.: Heterogeneous drop freezing in the immersion mode: model calculations considering soluble and insoluble particles in the drops, J. Atmos. Sci., 61, 2063-2072, doi:10.1175/1520-0469(2004)061<2063:HDFITI>2.0.CO;2, 2004.
Diehl, K., Simmel, M., and Wurzler, S.: Numerical sensitivity studies on the impact of aerosol properties and drop freezing modes on the glaciation, microphysics, and dynamics of clouds, J. Geophys. Res., 111, D07202, doi:10.1029/2005JD005884, 2006.

Doms, G. and Schättler, U.: A Description of the Nonhydrostatic Regional Model LM Part I: Dynamics and Numerics, Tech. rep., Deutscher Wetterdienst, Offenbach, Germany, 2002.

Durran, D. R.: Mountain waves and downslope winds, Atmospheric American Meteorological Society, Boston, 1990.

Findeisen, W.: Die kolloidmeteorologischen Vorgänge bei der Niederschlagsbildung (Colloidal meteorological processes in the formation of precipitation), Meteorol. Z., 55, 121-133, 1938.

Hoose, C., Lohmann, U., Stier, P., Verheggen, B., and Weingartner, E.: Aerosol processing in mixed-phase clouds in ECHAM5HAM: model description and comparison to observations, J. Geophys. Res., 113, D07210, doi:10.1029/2007JD009251, 2008.

Hueglin, C., Gehrig, R., Baltensperger, U., Gysel, M., Monn, C., and Vonmont, H.: Chemical characterisation of $\mathrm{PM}_{2.5}, \mathrm{PM}_{10}$ and coarse particles at urban, near-city and rural sites in Switzerland, Atmos. Environ., 39, 637-651, 2005.

Kirshbaum, D. J. and Durran, D. R.: Factors governing cellular convection in orographic precipitation, J. Atmos. Sci., 61, 682-698, doi:10.1175/1520-0469(2004)061<0682:FGCCIO>2.0.CO;2, 2004.

Lau, K. M. and Wu, H. T.: Warm rain processes over tropical oceans and climate implications, Geophys. Res. Lett., 30, 2290, doi:10.1029/2003GL018567, 2003.

Lebo, Z. J. and Morrison, H.: A Novel Scheme for Parameterizing Aerosol Processing in Warm Clouds, J. Atmos. Sci., 70, 35763598, doi:10.1175/JAS-D-13-045.1, 2013.

Lin, H. and Leaitch, R.: Development of an in-cloud aerosol activation parameterization for climate modelling, Paper presented at Workshop on Measurements of Cloud Properties for Forecasts of Weather, Air Quality and Climate, World Meteorol. Soc., Mexico City, 1997.

Lohmann, U.: Possible aerosol effects on ice clouds via contact nucleation, J. Atmos. Sci., 59, 647-656, doi:10.1175/15200469(2001)059<0647:PAEOIC>2.0.CO;2, 2002.

Lohmann, U.: Can anthropogenic aerosols decrease the snowfall rate?, J. Atmos. Sci., 61, 2457-2468, doi:10.1175/15200469(2004)061<2457:CAADTS>2.0.CO;2, 2004.

Lohmann, U. and Diehl, K.: Sensitivity studies of the importance of dust ice nuclei for the indirect aerosol effect on stratiform mixed-phase clouds, J. Atmos. Sci., 63, 968-982, doi:10.1175/JAS3662.1, 2006.

Lynn, B., Khain, A., Rosenfeld, D., and Woodley, W. L.: Effects of aerosols on precipitation from orographic clouds, J. Geophys. Res., 112, D10225, doi:10.1029/2006JD007537, 2007.

Mann, G. W., Carslaw, K. S., Ridley, D. A., Spracklen, D. V., Pringle, K. J., Merikanto, J., Korhonen, H., Schwarz, J. P., Lee, L. A., Manktelow, P. T., Woodhouse, M. T., Schmidt, A., Breider, T. J., Emmerson, K. M., Reddington, C. L., Chipperfield, M. P., and Pickering, S. J.: Intercomparison of modal and sectional aerosol microphysics representations within the same 3-D global chemical transport model, Atmos. Chem. Phys., 12, 4449-4476, doi:10.5194/acp-12-4449-2012, 2012.

Mitra, S., Brinkmann, J., and Pruppacher, H.: A wind tunnel study on the drop-to-particle conversion, J. Aerosol Sci., 23, 245-256, doi:10.1016/0021-8502(92)90326-Q, 1992. 
Muhlbauer, A. and Lohmann, U.: Sensitivity studies of the role of aerosols in warm-phase orographic precipitation in different dynamical flow regimes, J. Atmos. Sci., 65, 2522-2542, doi:10.1175/2007JAS2492.1, 2008.

Muhlbauer, A. and Lohmann, U.: Sensitivity studies of aerosolcloud interactions in mixed-phase orographic precipitation, J. Atmos. Sci., 66, 2517-2538, doi:10.1175/2009JAS3001.1, 2009.

Muhlbauer, A., Hashino, T., Xue, L., Teller, A., Lohmann, U., Rasmussen, R. M., Geresdi, I., and Pan, Z.: Intercomparison of aerosol-cloud-precipitation interactions in stratiform orographic mixed-phase clouds, Atmos. Chem. Phys., 10, 81738196, doi:10.5194/acp-10-8173-2010, 2010.

Posselt, R. and Lohmann, U.: Influence of Giant CCN on warm rain processes in the ECHAM5 GCM, Atmos. Chem. Phys., 8, 37693788, doi:10.5194/acp-8-3769-2008, 2008.

Pujol, O., Georgis, J.-F., Chong, M., and Roux, F.: Dynamics and microphysics of orographic precipitation during MAP IOP3, Q. J. Roy. Meteor. Soc., 131, 2795-2819, doi:10.1256/qj.04.79, 2005.

Saleeby, S. M., Cotton, W. R., Lowenthal, D., Borys, R. D., and Wetzel, M. A.: Influence of cloud condensation nuclei on orographic snowfall, J. Appl. Meteorol. Clim., 48, 903-922, doi:10.1175/2008JAMC1989.1, 2009.

Saleeby, S. M., Cotton, W. R., Lowenthal, D., and Messina, J.: Aerosol impacts on the microphysical growth processes of orographic snowfall, J. Appl. Meteorol. Clim., 52, 834-852, doi:10.1175/JAMC-D-12-0193.1, 2013.

Seifert, A. and Beheng, K. D.: A two-moment cloud microphysics parameterization for mixed-phase clouds. Part 1: Model description, Meteorol. Atmos. Phys., 92, 45-66, doi:10.1007/s00703005-0112-4, 2006.

Smith, R. B., Barstad, I., and Bonneau, L.: Orographic precipitation and Oregon's climate transition, J. Atmos. Sci., 62, 177-191, doi:10.1175/JAS-3376.1, 2005.

Spichtinger, P.: Eisübersättigte Regionen, Forschungsbericht FB2004-21, Deutsches Zentrum für Luft und Raumfahrt, PhD Thesis, Oberpfaffenhofen, 211 pp., 2004.

Steppeler, J., Doms, G., Schättler, U., Bitzer, H. W., Gassmann, A., Damrath, U., and Gregoric, G.: Meso-gamma scale forecasts using the nonhydrostatic model LM, Meteorol. Atmos. Phys., 82, 75-96, doi:10.1007/s00703-001-0592-9, 2003.

Stier, P., Feichter, J., Kinne, S., Kloster, S., Vignati, E., Wilson, J., Ganzeveld, L., Tegen, I., Werner, M., Balkanski, Y., Schulz, M., Boucher, O., Minikin, A., and Petzold, A.: The aerosol-climate model ECHAM5-HAM, Atmos. Chem. Phys., 5, 1125-1156, doi:10.5194/acp-5-1125-2005, 2005.

Twomey, S. A., Piepgrass, M., and Wolfe, T. L.: An assessment of the impact of pollution on global cloud albedo, Tellus B, 36, 356366, 1974.
Vali, G.: Nucleation terminology, J. Aerosol Sci., 16, 575-576, doi:10.1016/0021-8502(85)90009-6, 1985.

Vehkamäki, H., Kulmala, M., Napari, I., Lehtinen, K. E. J., Timmreck, C., Noppel, M., and Laaksonen, A.: An improved parameterization for sulfuric acid-water nucleation rates for tropospheric and stratospheric conditions, J. Geophys. Res., 107, 4622, doi:10.1029/2002JD002184, 2002.

Vignati, E., Wilson, J., and Stier, P.: M7: an efficient sizeresolved aerosol microphysics module for large-scale aerosol transport models, J. Geophys. Res., 109, D22202, doi:10.1029/2003JD004485, 2004.

Wegener, A.: Thermodynamik der Atmosphäre, J. A. Barth, Leipzig, 1911.

Weingartner, E., Nyeki, S., and Baltensperger, U.: Seasonal and diurnal variation of aerosol size distributions $(10<D<750 \mathrm{~nm})$ at a high-alpine site (Jungfraujoch $3580 \mathrm{~m}$ asl), J. Geophys. Res., 104, 26809-26820, doi:10.1029/1999JD900170, 1999.

Xue, L., Teller, A., Rasmussen, R., Geresdi, I., and Pan, Z.: Effects of aerosol solubility and regeneration on warm-phase orographic clouds and precipitation simulated by a detailed bin microphysical scheme, J. Atmos. Sci., 67, 3336-3354, doi:10.1175/2010JAS3511.1, 2010.

Xue, L., Teller, A., Rasmussen, R., Geresdi, I., Pan, Z., and Liu, X.: Effects of aerosol solubility and regeneration on mixed-phase orographic clouds and precipitation, J. Atmos. Sci., 69, 1994 2010, doi:10.1175/JAS-D-11-098.1, 2012.

Young, K. C.: A numerical simulation of wintertime, orographic precipitation: Part I. Description of model microphysics and numerical techniques, J. Atmos. Sci., 31, 1735-1748, doi:10.1175/1520-0469(1974)031<1735:ANSOWO>2.0.CO;2, 1974a.

Young, K. C.: The role of contact nucleation in ice phase initiation in clouds, J. Atmos. Sci., 31, 768-776, doi:10.1175/15200469(1974)031<0768:TROCNI>2.0.CO;2, 1974b.

Zhao, H.-B. and Zheng, C.-G.: Stochastic algorithm and numerical simulation for drop scavenging of aerosols, Appl. Math. Mech.Engl., 27, 1321-1332, doi:10.1007/s10483-006-1004-z, 2006.

Zubler, E. M., Folini, D., Lohmann, U., Lüthi, D., Muhlbauer, A., Pousse-Nottelmann, S., Schär, C., and Wild, M.: Implementation and evaluation of aerosol and cloud microphysics in a regional climate model, J. Geophys. Res., 116, D02211, doi:10.1029/2010JD014572, 2011a.

Zubler, E. M., Lohmann, U., Lüthi, D., Schär, C., and Muhlbauer, A.: Statistical analysis of aerosol effects on simulated mixed-phase clouds and precipitation in the Alps, J. Atmos. Sci., 68, 1474-1492, doi:10.1175/2011JAS3632.1, 2011b. 